\title{
Colloidal-ALD-Grown Core/Shell CdSe/CdS Nanoplatelets as Seen by DNP Enhanced PASS-PIETA NMR Spectroscopy
}

\author{
Laura Piveteau, Dmitry N. Dirin, Christopher P. Gordon, Brennan J. Walder, Ta-Chung Ong, \\ Lyndon Emsley, Christophe Copéret,* and Maksym V. Kovalenko*
}

Cite This: Nano Lett. 2020, 20, 3003-3018

Read Online

\section{ACCESS | Llll Metrics \& More | 回 Article Recommendations | (s) Supporting Information}

ABSTRACT: Ligand exchange and CdS shell growth onto colloidal CdSe nanoplatelets (NPLs) using colloidal atomic layer deposition (c-ALD) were investigated by solid-state nuclear magnetic resonance (NMR) experiments, in particular, dynamic nuclear polarization (DNP) enhanced phase adjusted spinning sidebands-phase incremented echo-train acquisition (PASS-PIETA). The improved sensitivity and resolution of DNP enhanced PASS-PIETA permits the identification and study of the core, shell, and surface species of $\mathrm{CdSe}$ and $\mathrm{CdSe} / \mathrm{CdS}$ core/shell NPLs heterostructures at all stages

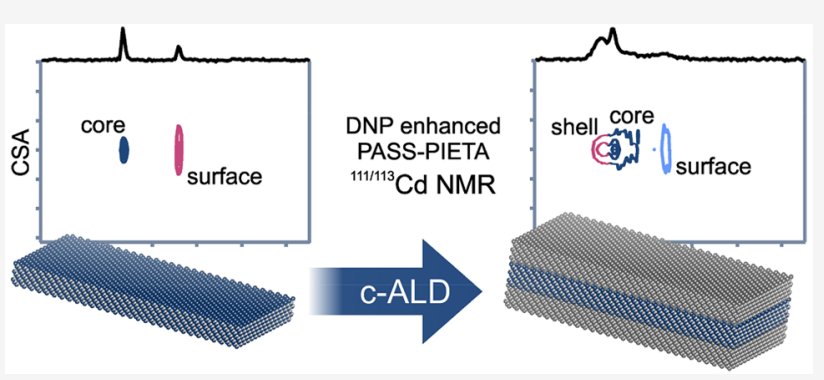
of c-ALD. The cadmium chemical shielding was found to be proportionally dependent on the number and nature of coordinating chalcogen-based ligands. DFT calculations permitted the separation of the the ${ }^{111 / 113} \mathrm{Cd}$ chemical shielding into its different components, revealing that the varying strength of paramagnetic and spin-orbit shielding contributions are responsible for the chemical shielding trend of cadmium chalcogenides. Overall, this study points to the roughening and increased chemical disorder at the surface during the shell growth process, which is not readily captured by the conventional characterization tools such as electron microscopy.

KEYWORDS: nanocrystals, nanoplatelets, c-ALD, PASS-PIETA, dynamic nuclear polarization, solid-state NMR

C olloidal semiconductor nanocrystals (NCs) are of continued interest for basic and applied research, owing to their unique size-dependent electronic and optical properties. $^{1-3}$ Cadmium chalcogenide CdE $(\mathrm{E}=\mathrm{S}$, Se, Te) NCs represent a canonical system, on which the experimental and theoretical models have been developed regarding NC synthesis, surface chemistry, and physical properties. Compared to other semiconductor NC systems, CdSe NCs have been synthesized with the far largest control over composition, size, and shape. ${ }^{4-10}$ Consequently, the engineerability of the electronic properties of cadmium chalcogenide NCs remains unmatched. ${ }^{4,7,10,11}$

Two-dimensional zinc-blende (ZB) CdSe nanoplatelets (NPLs) represent a unique colloidal quantum well material. $^{12-25}$ Their small thickness of just $1-2 \mathrm{~nm}$ (3-6 CdSe monolayers $)^{13,22,26}$ is an order of magnitude smaller than their typical lateral dimensions (tens of $\mathrm{nm}$ ). ${ }^{14}$ This results in strong one-dimensional quantum confinement of the exciton and, hence, the name "quantum wells", owing to the large excitonic Bohr radius of CdSe (5-6 nm). In ZB CdSe NPLs, as well as in CdS and CdTe NPLs, the thickness of the individual platelets can be controlled precisely in steps of a stoichiometric monolayer by adjusting synthesis conditions. ${ }^{12,14,22,27-29}$ Moreover, the surface of these NPLs is atomically flat, which diminishes inhomogeneous spectral broadening of the excitonic features in the absorption and emission spectra. ${ }^{13}$
This gives rise to a unique electronic structure and optical properties, including narrowband photoluminescence (PL) from ensembles and single NPLs $(<40 \mathrm{meV})$, fast radiative rates (fluorescence lifetimes of ca. $1 \mathrm{~ns}$ at $6 \mathrm{~K}$ ), small Stokes shifts $(<3 \mathrm{meV})$, and many more. ${ }^{11,13,14,30-37}$

A popular approach to enhance the optical properties of $\mathrm{CdE}(\mathrm{E}=\mathrm{S}$, Se, Te) NPLs, foremost to maximize their PL quantum yield (QY) and to impart suited environmental stability, invokes epitaxial overgrowth of the NPLs with another, wider-band gap semiconductor shell. Core/shell $\mathrm{CdSe} / \mathrm{CdS}$ NPLs ${ }^{16,26,38,39}$ and $\mathrm{CdSe} / \mathrm{ZnS} \mathrm{NPLs}^{39-42}$ are thus by far the most commonly studied colloidal NPL heterostructures. The most recent additions to the class of colloidal NPLs are CdSe/CdS/CdSe, ${ }^{27} \mathrm{CdSe} / \mathrm{CdS} / \mathrm{ZnS},{ }^{42}$ and $\mathrm{CdSe} / \mathrm{CdSe} / \mathrm{CdZnS}$ core/shell1/shell2 NPLs. ${ }^{42,43}$ With the epitaxial extension of the crystallites, the band gap and other physical parameters are substantially altered. ${ }^{13,16,18,25-27,29,38-63}$ For instance, the PL QY raises from about $30 \%$ for core-only CdSe NPLs (green-emissive, 4.5

Received: November 24, 2019

Revised: February 5, 2020

Published: February 20, 2020 
monolayers thick) to $85-98 \%$ upon the addition of a widerband gap shell (red-emissive). ${ }^{41}$ With the goal of putting the exceptional PL properties to work, numerous applications of CdSe-based NPLs are being pursued, e.g., light-emitting devices, $^{64-70}$ solar cells, ${ }^{67,71}$ photodetectors, ${ }^{72,73}$ and lasers. $^{13,28,33,42,47,74-77}$

The versatility in the growth of heterostructures has increased in the past few years such that the thickness is

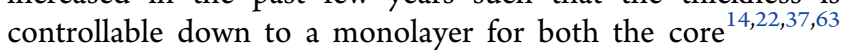
and the shell. ${ }^{16,27,40,41,43,49}$ Furthermore, lateral extension of the platelet with a chemically distinct material is possible without altering the NPL thickness, forming what are known as core/crown NPLs. ${ }^{25,44-48,78}$ A complete enclosure of the NPL core is attainable as well, thereby harnessing the benefits of both the core/shell and core/crown heterostructures. ${ }^{18,29}$ The $\mathrm{PL}$ tuning range obtainable with these different NPL compositions encompasses a wide range from $395 \mathrm{~nm}$ (coreonly CdSe NPLs) $)^{12,14}$ to $720 \mathrm{~nm}$ (6-monolayer-CdSe/CdS/ $\mathrm{ZnS}$ core/shell1/shell2 NPLs). ${ }^{42}$ While the thickness of the NPLs directly influences their band gap energy in discrete steps, a more continuous (fine) tuning of the NPLs emission wavelength can be obtained compositionally by the formation of solid solutions of the pristine NPLs (e.g., $\mathrm{CdSe}_{1-x} \mathrm{~S}_{x}$ NPLs, $\left.{ }^{17,18} \mathrm{CdS}_{x} \mathrm{Se}_{1-x} \mathrm{NPLs}^{20}{ }^{20} \mathrm{CdSe}_{1-x} \mathrm{Te}_{x} \mathrm{NPL}\right),{ }^{79}$ or likewise adjusting shell and crown compositions, ${ }^{26,27,42,43,46-48,77}$ or by doping the CdSe NPLs with Ag to introduce lower-energy transitions via midgap trap states. ${ }^{80}$ Next to the formation of heterostructures, diverse postsynthetic chemical modifications are pursued to impart desired optical and electronic characteristics of NPLs. These include the exchange of insulating longchain ligands with mercaptopropionic acid, $\mathrm{OH}^{-}$and $\mathrm{SH}^{-}$for solar light sensitization of metal-oxide nanorods, ${ }^{81}$ various alkyl thiols, ${ }^{19,82}$ or halide ligands. ${ }^{83}$ The latter shifts the optical signals to the red, releases lattice strain in cadmium chalcogenide NPLs, and passivates the surface, which maintains or even enhances the high PL QY of NPLs. ${ }^{83}$ Cation-exchange reactions are yet another promising avenue. For example, mercury chalcogenide NPLs ${ }^{84,85}$ and $\mathrm{HgTe} / \mathrm{CdS}$ core/shell NPL heterostructures have been reported. ${ }^{86}$ These materials are of interest for light emission and detection in the near- and mid-infrared spectral regions. More elaborate synthetic pathways are within reach as well, such as sequential cation exchange first with $\mathrm{Cu}^{+}$and then with $\mathrm{Zn}^{2+}$ and $\mathrm{Pb}^{2+}$ ions. These results in zinc- and lead-chalcogenide-based core and core/shell NPLs highlight an unmatched versatility of the NPLs in comparison to other colloidal nanostructures. ${ }^{87}$

The atomic-level details of these chemical transformations, namely, shelling or crowning, cation-exchange, and ligandexchange processes, are typically elucidated and traced indirectly by their influence on optical and electronic properties. Electron microscopy and X-ray diffraction complement such analyses.

In this work, we show how solid-state nuclear magnetic resonance (NMR) spectroscopy can be used as a powerful tool toward understanding the chemical reactions involving colloidal NPLs and obtaining atomistic insights not accessible by other characterization methods. Herein, we focus on the $\mathrm{CdSe} / \mathrm{CdS}$ core/shell NPLs grown by colloidal atomic layer deposition (c-ALD). c-ALD was first described in 2012 for growing $\mathrm{CdS}$ shells atop of spherical CdSe NCs and CdSe NPLs. ${ }^{88}$ This postsynthetic surface process allows for precise growth of CdS shells and involves a sequence of surface reactions: removal of organic ligands, successive addition of sulfide and cadmium ions, and reattachment of organic ligands. These reaction steps are iterated to grow the $\mathrm{CdS}$ shell as desired. c-ALD is a highly suited synthetic procedure to study the surface chemistry ex situ, in a step-by-step manner, as the isolation steps are an inherent part of the procedure. Furthermore, at every stage, a distinctly different surface reaction is utilized, and therefore, different kinds of surface termination are produced. Thanks to recent developments discussed below, NMR spectroscopy offers ex situ snapshots of the c-ALD process at a level of atomic and molecular detail that cannot currently be matched by any other characterization method.

NMR spectroscopy is increasingly capable of characterizing complex materials systems and readily addresses the challenges of low species concentration, surface disorder, reduced crystallinity, and other forms of structural variability within the sample. With solution and solid-state NMR methods, different kinds of NCs, as well as different parts (core, shell, surface, etc.) of a specific kind of semiconductor NC, can be sampled because many chemical elements constituting these NCs possess at least one NMR-active isotope (e.g., ${ }^{1} \mathrm{H},{ }^{13} \mathrm{C}$, $\left.{ }^{31} \mathrm{P},{ }^{77} \mathrm{Se},{ }^{111} \mathrm{Cd},{ }^{113} \mathrm{Cd},{ }^{123} \mathrm{Te},{ }^{125} \mathrm{Te}\right)$. While solution $\mathrm{NMR}$ spectroscopy has mostly been restrained to NC ligands, ${ }^{1,89-91}$ solid-state NMR can also sample and resolve the core and the surface of colloidal NCs. ${ }^{92-100}$ However, for many isotopes relevant to NCs, conventional NMR experiments are challenging due to low natural abundance and weaker nuclear magnetism compared to more common NMR nuclei such as ${ }^{1} \mathrm{H}$, rendering signals practically unobservable. If surface species are to be observed, their low concentration further reduces the intensity of the signals of interest from low abundance and/or low gyromagnetic ratio nuclei. Thus, numerous methods for enhancing the NMR signal have been developed. Cross-polarization magic-angle-spinning (CP MAS) methods for transferring the greater polarization of protons to other nuclei are standard approaches for improving sensitivity when applicable (i.e., when protons are in molecular proximity to the target nucleus), ${ }^{101,102}$ and it has been successfully applied to semiconductor NC systems. ${ }^{99,100}$ In the past decade, dynamic nuclear polarization (DNP) enhanced NMR spectroscopy has matured into a particularly powerful tool for characterizing inorganic materials at an atomic level. ${ }^{103-106}$ In DNP, the polarization of unpaired electrons, which is 3 to 4 orders of magnitude greater than that of most nuclei, is transferred to the nuclei of interest. When a source of electron polarization (e.g., nitroxide biradicals) is added exogenously to a target solid, NMR signals of species at the surface of the solid are enhanced selectively. ${ }^{103,107,108}$ Signal enhancement factors of up to 2 orders of magnitude can be achieved compared to conventional solid-state NMR experiments, and with suitable formulations, a diverse range of materials can be probed, ranging from porous catalytic materials ${ }^{103}$ to cements ${ }^{109}$ and DNA microarrays on glass slides. ${ }^{110}$ Recently, we have developed a facile sample formulation methodology that can be used to acquire DNP enhanced NMR spectra of colloidal nanomaterials in their native colloidal state using minute quantities of the analyte (several milligrams per sample). ${ }^{97,98}$ Enhancement factors of 10-100 (for InP, CdSe, CdTe, PbTe, PbSe NCs, with organic and inorganic capping ligands) were obtained by impregnating colloidal-radical solutions with mesoporous silica (meso- $\mathrm{SiO}_{2}$ ), leading to 100-10000 times shorter experiment times for obtaining comparable signal-to-noise ratios. ${ }^{97,98}$ These were 

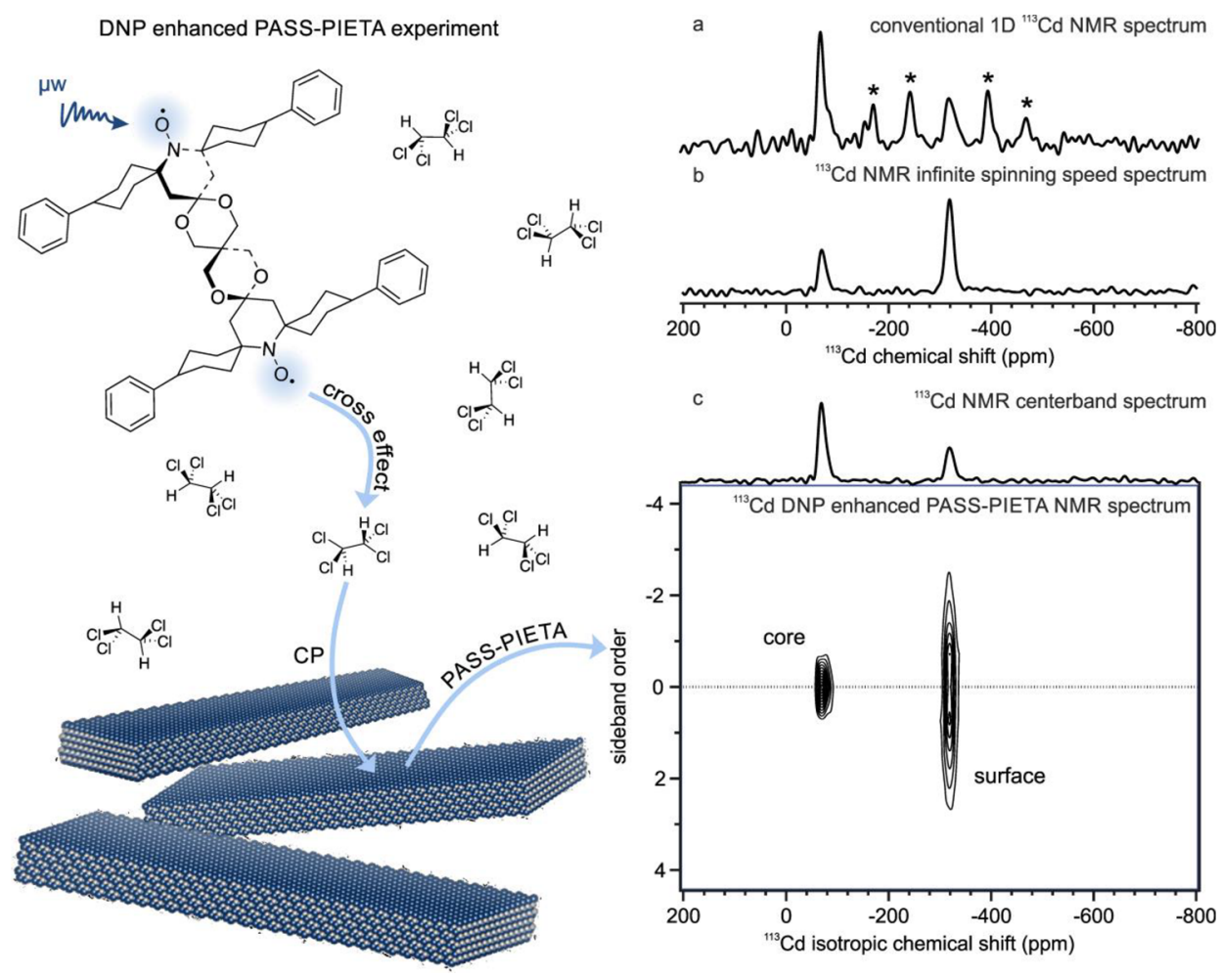

Figure 1. On the left, a scheme of a DNP enhanced phase adjusted spinning sideband-phase incremented echo-train acquisition (PASS-PIETA) NMR experiment is depicted on the example of ZB CdSe NPLs dispersed in 1,1,2,2-tetrachloroethane (TCE). Continuous microwave ( $\mu \mathrm{w}$ ) irradiation leads to spontaneous polarization transfer from the unpaired electron spins; in the present example, the biradical TEKPol, ${ }^{119}$ to the proton spins. Solvents of colloidal solutions often contain protons, and TCE provides a particularly well-suited proton bath for DNP experiments as it exhibits glass-forming properties and solubilizes organic ligand-capped colloidal NCs well. ${ }^{97,98,120}$ In DNP experiments, the proton polarization is transferred in an additional CP step to the nuclei of interest where it is either detected or goes through a more complex pulse sequence such as PASS-PIETA before being acquired. (a-c) DNP enhanced NMR spectra of ZB CdSe NPLs at $14.1 \mathrm{~T}, 100 \mathrm{~K}$, and $10 \mathrm{kHz}$ MAS. In the conventional ID NMR spectrum (a), spinning sidebands (marked with asterisks) complicate identification of individual species, as is evident by comparing with (b) the effective infinite spinning speed spectrum, which can be obtained either by spinning much faster than the span of the anisotropy or by reconstruction from the PASS-PIETA spectrum (c). In the PASS-PIETA spectrum, both core and surface are resolved, and spinning sidebands are retained, allowing quantification of CSA by fitting profiles in the sideband order dimension. The obtained intensities are proportional to the excited spin populations, but not to the number of atoms, due to the surface enhancement. The centerband spectrum, which corresponds to the slice at zero sideband order (dashed line), is displayed as the isotropic spectrum above every PASS-PIETA spectrum. This choice enhances the relative intensity of the core species in the sideband-free spectrum.

the first examples of a growing catalog of dispersal strategies for DNP enhanced NMR spectroscopy of NCs, ${ }^{11-113}$ which facilitates experiments on difficult isotopes, such as those that have low gyromagnetic ratios, low natural abundance, and/or low concentration. Importantly, multidimensional NMR experiments, which enhance spectral resolution and information and permit analysis of surface structure and complexity and were previously considered impossible for these systems due to the signal averaging time required, are now within reach. ${ }^{94,97,98,103-106}$ One such experiment is the ${ }^{113} \mathrm{Cd}$ twodimensional phase adjusted sideband separation (2D-PASS) $\mathrm{NMR}^{114,115}$ experiment on NCs. ${ }^{94}$ 2D-PASS provides improved spectral resolution and better accessibility to structural information by separating the isotropic chemical shift and the chemical shift anisotropy (CSA). Previously, we showed that 2D-PASS, when combined with signal enhancing methods such as DNP and phase incremented echo-train acquisition (PIETA), ${ }^{116}$ can cope with the low concentration of surface species, the low abundance of ${ }^{113} \mathrm{Cd}$ isotopes and the high disorder, anisotropy, and asymmetry of NC surface species and, therefore, meets all requirements to study surface species of colloidal semiconductor NCs. ${ }^{94}$
In this work, we use DNP enhanced PASS-PIETA NMR to study the stepwise growth of one monolayer of a CdS shell onto atomically flat ZB CdSe NPLs during c-ALD. We assign the NMR signals to core and surface species for bare ZB CdSe NPLs and at intermediate steps of the shell growth and then rationalize the chemical reactions at the NC surface. With the aid of density functional theory (DFT) calculations, we rationalize the trends in the ${ }^{111 / 113} \mathrm{Cd}$ chemical shifts; in particular, in relation to the paramagnetic and spin-orbit shielding through a natural chemical shielding analysis. ${ }^{117,118}$ An overarching finding of this work is that NMR spectroscopy can capture those degrees of chemical and structural disorder, which are not readily addressable with electron microscopy or $\mathrm{X}$-ray diffraction, but which play a paramount role in the control of optical properties.

Results and Discussion. DNP Enhanced PASS-PIETA NMR Experiment. The interpretation and acquisition of solidstate NMR spectra of NCs are challenging due to the intrinsically low sensitivity of the relevant nuclei, such as ${ }^{113} \mathrm{Cd}$, and the small size of the crystallites as well as the absence of long-range atomic order. These disadvantages lead to spectrally inhomogeneous broadening from a chemical 
Table 1. CSA Parameters of ZB CdSe NPLs at Different Stages of c-ALD Obtained by Fitting the Indirect Dimension of their DNP Enhanced PASS-PIETA Spectra ${ }^{a}$

\begin{tabular}{|c|c|c|c|c|}
\hline NPL sample & $\delta_{\text {iso }}(\mathrm{ppm})$ & species & CSA parameters & $\chi^{2}$ \\
\hline \multirow[t]{2}{*}{$\mathrm{CdSe}-\mathrm{OA}$} & -311 & surface $\mathrm{Cd}$-oleate & $\Delta=-250 \pm 20 \mathrm{ppm}, \eta>0.9$ & 48.9 \\
\hline & -62 & core $\mathrm{CdSe}$ & $|\Delta|<40 \mathrm{ppm}$ & 12.6 \\
\hline $\mathrm{CdSe} / \mathrm{S}^{2-}$ & $\begin{array}{l}-162 \text { to } 0 \\
(\max -52)\end{array}$ & core CdSe & $\begin{array}{c}\Delta_{1}=-240 \pm 40 \mathrm{ppm}, \eta_{1}=0.85 \pm 0.15 \\
\Delta_{2}=0 \mathrm{ppm}\end{array}$ & 21.2 \\
\hline \multirow[t]{5}{*}{$\mathrm{CdSe} / \mathrm{S}^{2-} / \mathrm{Cd}^{2+}$} & -633 & free $\mathrm{Cd}(\mathrm{OAc})_{2}$ & $|\Delta|<120 \mathrm{ppm}$ & 19.2 \\
\hline & -392 & naked surface $\mathrm{Cd}$ & $\Delta=-210 \pm 20 \mathrm{ppm}, \eta=0.7 \pm 0.2$ & 24.8 \\
\hline & -289 & surface Cd-acetate & $\Delta=-305 \pm 20 \mathrm{ppm}, \eta=0.75 \pm 0.1$ & 41.9 \\
\hline & -46 & core $\mathrm{CdSe}$ & $|\Delta|<160 \mathrm{ppm}$ & 16.7 \\
\hline & 12 & CdS shell & $|\Delta|<110 \mathrm{ppm}$ & 13.9 \\
\hline \multirow[t]{2}{*}{$\mathrm{CdSe} / \mathrm{CdS}-\mathrm{OAm}$} & -261 & surface Cd-acetate & $\Delta=-320 \pm 40$ ppm, $\eta=0.8 \pm 0.2$ & 86.0 \\
\hline & $\begin{array}{c}-200 \text { to } 40 \\
(\max -41,18)\end{array}$ & core CdSe and CdS shell & $\begin{array}{c}\Delta_{1}=-245 \pm 15 \mathrm{ppm}, \eta_{1}=0.95 \pm 0.05 \\
\Delta_{2}=0\end{array}$ & 12.1 \\
\hline
\end{tabular}

${ }^{a}$ According to the Haeberlen-Mehring-Spiess convention, the $\delta_{\text {iso }}$ (isotropic chemical shift) and the CSA parameters $\Delta$ (anisotropy) and $\eta$ (asymmetry) are related to the principal tensor elements $\delta_{x x}, \delta_{y y}$, and $\delta_{z z}$, whose values are assigned to satisfy the ordering: $\left|\delta_{z z}-\delta_{\text {iso }}\right| \geq\left|\delta_{x x}-\delta_{\text {iso }}\right|$ $\geq\left|\delta_{y y}-\delta_{\text {iso }}\right|$. Based on this expression, $\delta_{\text {iso }}, \Delta$, and $\eta$ are given by $\delta_{\text {iso }}=\frac{1}{3}\left(\delta_{x x}+\delta_{y y}+\delta_{z z}\right), \Delta=\delta_{z z}-\delta_{\text {iso }}$, and $\eta=\frac{\delta_{y y}-\delta_{x x}}{\Delta}$.

disorder of surface species and frequency anisotropy. To overcome the problem of the low sensitivity of ${ }^{113} \mathrm{Cd}$ nuclei, we have enhanced the NMR signal by DNP. In a typical DNP experiment on colloidal NCs, as illustrated in the left panel of Figure 1, a radical, most often a nitroxide biradical such as TEKPol or AMUPol, ${ }^{119,121}$ is added to the sample as an exogeneous source of unpaired electrons. Then, continuous irradiation with microwaves spontaneously hyperpolarizes the protons of the solvent molecules by the cross effect. ${ }^{122}$ The polarization is afterward transferred from the protons to the nuclei of interest by $\mathrm{CP}$, which produces an effective surface enhancement of the analyte. ${ }^{107}$

The right panel of Figure 1 introduces ZB CdSe NPLs as studied by DNP-enhanced NMR. Experiments are carried out under magic-angle spinning (MAS), where the sample is rotated around the so-called magic angle of $54.74^{\circ}$ with respect to the applied magnetic field. This improves resolution by averaging the CSA, splitting the NMR signal of a given site into a centerband at its isotropic chemical shift, flanked by spinning sidebands at integer multiples of the spinning frequency. This is shown in Figure 1a, where spinning sidebands at $10 \mathrm{kHz}$ MAS render the ${ }^{113} \mathrm{Cd}$ isotropic chemical shifts of the $\mathrm{ZB} \mathrm{CdSe}$ NPLs difficult to discern. These sidebands can be suppressed by spinning faster, which would eventually afford a spectrum resembling that in Figure $1 \mathrm{~b}$, where two distinct sites are readily resolved.

Limitations on the sample rotation rate often prevent MAS alone from sufficiently simplifying the NMR spectrum. To further improve resolution, the isotropic chemical shift contribution can be separated from the anisotropic one in a two-dimensional NMR experiment such as DNP enhanced PASS-PIETA, as shown for ZB CdSe NPLs in Figure 1c. This 2D NMR spectrum has several advantages compared to not only conventional 1D NMR spectra (Figure 1a) but also effective infinite spinning speed spectra (Figure $1 \mathrm{~b}$ ). Unlike the latter, the PASS-PIETA spectrum (Figure 1c) retains information about the spin surroundings in the form of the spinning sideband manifolds in the indirect dimension. Furthermore, the effective infinite spinning speed spectrum can be reconstructed from the PASS-PIETA spectrum by the summation projection of the sideband order dimension. Indeed, this is how Figure $1 \mathrm{~b}$ was obtained. However, the signal-to-noise ratio of highly symmetric species with small CSAs is reduced in the projection relative to other species due to the accumulation of noise in the projection. We, therefore, opt for displaying the centerband spectrum, i.e., the slice in the PASS-PIETA spectrum at zero sideband order, as it presents the isotropic chemical shift distributions with the enhancement of species possessing small CSAs, which generally have lower intensity in the systems we study. This effect can be seen by comparing Figure 1b, where the intensities reflect the excited spin populations, to the centerband spectrum in Figure 1c.

Additional information pertaining to the magnetic environment of a spin, particularly its local symmetry, is encoded by the CSA. Generally, smaller CSAs suggest more symmetric chemical environments. The CSA can be quantified by fitting the spinning sideband patterns obtained from the sideband order dimension of DNP enhanced PASS-PIETA spectra to yield the CSA tensor parameters of specific chemical sites, as resolved by their isotropic chemical shifts. With quantification of the CSA, one could corroborate structural hypotheses by comparing them with the results from quantum mechanical calculations such as $\mathrm{DFT}^{123}$ or Hartree-Fock theory, ${ }^{124}$ presently not within reach for extended inorganic solids.

We describe the CSA by its anisotropy $(\Delta)$ and asymmetry $(\eta)$ according to the Haeberlen-Mehring-Spiess convention. ${ }^{125,126}$ A large CSA (i.e., with a large anisotropy $\Delta$ ), induced by a highly asymmetric spin surrounding, produces broader signals and, hence, more crowded 1D NMR spectra. Our results for the NC systems acquired at different stages of c-ALD are given in Table 1, with the first row corresponding to our present example of ZB CdSe NPLs. $\chi^{2}$ in Table 1 is the noise-weighted sum of squared residuals. For more details about the fitting procedures and the models used, we refer to the Details about Sideband Pattern Fit to Extract CSA Parameters section in the Supporting Information.

c-ALD of CdS Shell on CdSe NPLs. c-ALD is a highly suited synthetic procedure to study the surface chemistry ex situ, in a step-by-step manner, as the isolation steps are an inherent part of c-ALD. However, only little is known about the processes 
colloidal atomic layer deposition (C-ALD)

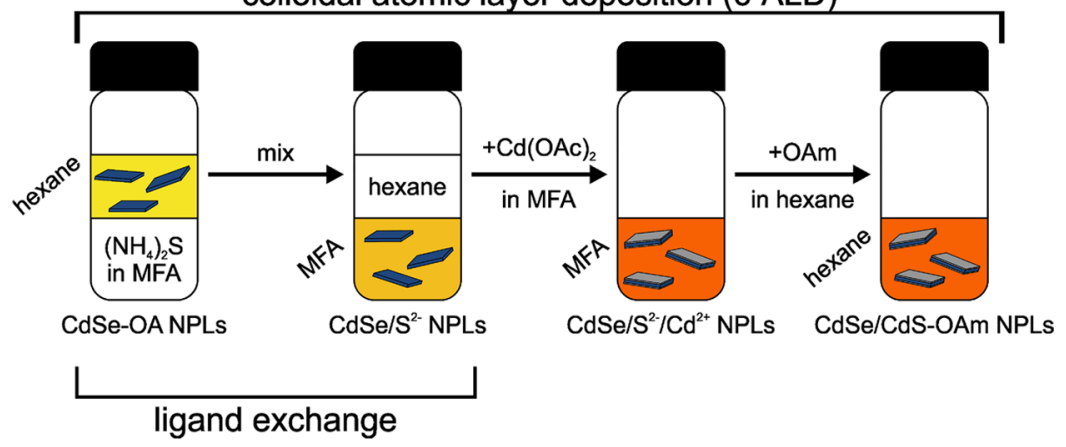

Figure 2. Scheme of CdS shell (gray) growth onto ZB CdSe nanoplatelets (NPLs, dark blue) by colloidal atomic layer deposition (c-ALD). The first step is a ligand exchange (LE) reaction during which the long oleate (OA) ligands are exchanged by short, inorganic sulfide ligands. Thereby, the NPLs are transferred from an apolar (hexane) to a polar phase ( $N$-methylformamide, MFA). The shell layer is completed by the addition of cadmium acetate in MFA to the reaction mixture. As the last step, the addition of oleylamine (OAm) in hexane permits the transfer of the colloidal $\mathrm{CdSe} / \mathrm{CdS}$ core/shell NPLs back to the apolar phase, thereby passivating the NPL surface. The shell growth reduces the electronic confinement and influences the optical properties of the NPLs, as observed by the changing color of the colloidal solution.

taking place during organic-to-inorganic ligand exchange (LE, an integral part of the c-ALD) and other steps of c-ALD. The characterization of the organic ligands of the pristine NCs is well-established, involving numerous analytical methods such as solution-state $\mathrm{NMR}^{89,127-133}$ and infrared spectroscopy. ${ }^{108,134-137}$ A more inclusive spectroscopic observation of the NC surface (e.g., including surface atoms to which ligands bind and various other surface species) and NC core has remained a prohibitively challenging task. ${ }^{138}$ In this context, solid-state NMR spectroscopy ${ }^{94,97,98,100,139-141}$ and synchrotron X-ray absorption spectroscopy ${ }^{141-152}$ are highly instrumental. These have led to additional atomistic insights into the structure of NCs. ${ }^{92,94-100,131,139-143,150-154}$ In this work, we continue our efforts to develop a suite of NMR methods for the characterization of colloidal nanomaterials and focus on $\mathrm{ZB}$ CdSe NPLs and c-ALD-grown CdSe/CdS NPLs.

Oleate-capped ZB CdSe NPLs (CdSe-OA NPLs in hexane) are the starting point of the c-ALD reaction. The NPLs' synthesis and the c-ALD are based on procedures reported by Ithurria et al. ${ }^{12,14,88}$ A scheme of the stepwise $\mathrm{CdS}$ shell growth onto CdSe NPLs by c-ALD is depicted in Figure 2. In the first step, the long aliphatic ligands of the as-synthesized CdSe NPLs are replaced by short, charged, inorganic sulfide ligands from $\left(\mathrm{NH}_{4}\right)_{2} \mathrm{~S}$ by an LE reaction. ${ }^{155,156}$ As a consequence, the mechanism of colloidal stabilization is switched from the shortrange steric repulsion of hydrocarbon chains to a long-range electrostatic repulsion of the anion-charged surfaces. During LE, the NPLs are transferred into the polar solvent, MFA, yielding sulfide-capped ZB CdSe NPLs (CdSe/S ${ }^{2-}$ NPLs in MFA). These are purified from the excess sulfide ions by precipitation with antisolvents (acetonitrile (ACN)/toluene mixture) and then centrifuged and redispersed again in MFA. To the purified CdSe/S ${ }^{2-}$ NPLs in MFA, a $\mathrm{Cd}(\mathrm{OAc})_{2}$ solution in MFA is added as a $\mathrm{Cd}$ precursor. The completion of the CdS monolayer leads to switching of the surface charge of the NPLs from negative to positive (see $\zeta$ potentials in Table S1). Subsequent precipitation with toluene as an antisolvent removes the excess cadmium precursor. One can obtain these core/shell particles either in MFA $\left(\mathrm{CdSe} / \mathrm{S}^{2-} / \mathrm{Cd}^{2+} \mathrm{NPLs}\right.$ in MFA) by redispersing the colloids in MFA or in hexane by adding a hexane-oleylamine (OAm) solution ( CdSe/CdSOAm NPLs in hexane). From TEM images taken after the four stages of c-ALD, we could conclude that the shape and lateral size of the NPLs remained unchanged throughout the complete c-ALD process (Figure S1). However, the optical properties, namely, absorption and emission spectra, of the platelets undergo a large red-shift (see Figure 3, panels $1 c-4 c$ ), similar to reports in the literature. ${ }^{13,88}$ This is a clear indication that the electronic confinement is reduced as the CdS shell forms a quasi-Type II band alignment in these core/shell material systems (core-localized holes, delocalized electrons).

ZB CdSe NPLs and their derivatives have already been intensively studied, in particular, their optoelectronic properties $^{14-18,29,30,38,48,157}$ and their growth mechanism. ${ }^{24,63,158-162}$ Nevertheless, very little is known as to how the surface of these NPLs looks like (roughness, topology, etc.) and what species are present. ${ }^{108,159,163,164}$

Oleate-Capped ZB CdSe NPLs in Hexane. Pristine ZB CdSe NPLs emit at $511 \mathrm{~nm}$ and have dimensions of $10-15 \mathrm{~nm}$ $\times 20-30 \mathrm{~nm} \times 1.5 \mathrm{~nm}$. They appear as excellent model systems for investigating surface chemistry reactions such as cALD because of their large and atomically flat surfaces. Their DNP enhanced PASS-PIETA spectrum (Figures 1 and 3, panel $1 \mathrm{~b}$ ) is in good agreement with our earlier report. ${ }^{94}$ They were found to have a cadmium-terminated surface, on which every single cadmium atom is coordinating to a carboxylate ligand, e.g., oleate or myristate. This is in agreement with the high, measured ligand density of $5.3 \mathrm{~nm}^{-2} .{ }^{164}$ The two large basal (001) facets, which constitute about $80 \%$ of the overall surface of these NPLs, yield four times the NMR signal than the remaining $20 \%$ of surface cadmium atoms at side facets and exhibit only minimal surface disorder after colloidal synthesis. ${ }^{14,24}$ The side facets are not distinguishable at the signalto-noise ratio achieved in this work. On the basis of our previously reported data, ${ }^{94,97}$ we conclude that the signal at $-62 \mathrm{ppm}$ belongs to core CdSe and exhibits a small CSA $(|\Delta|$ $<40 \mathrm{ppm}$, see Table 1) due to its isotropic, crystalline surrounding inside the NPLs. In other words, this signal exhibits a bulk-like character, which has also been predicted by DFT calculations. ${ }^{163}$ The signal with a larger CSA of about $\Delta$ $=-250 \mathrm{ppm}$ with an almost axial symmetry at $\delta_{\text {iso }}=-311 \mathrm{ppm}$ (see Table 1) is engendered by the surface cadmium atoms coordinated to a carboxylate ligand, experiencing a highly asymmetric surrounding due to the crystallite-solvent interface. 
$1 a$

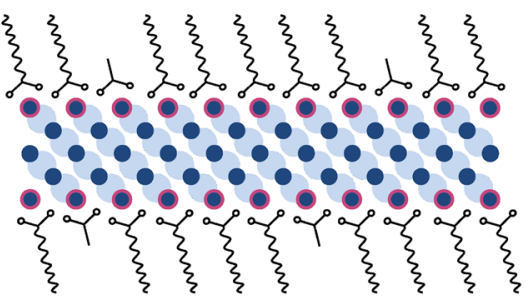

$2 a$

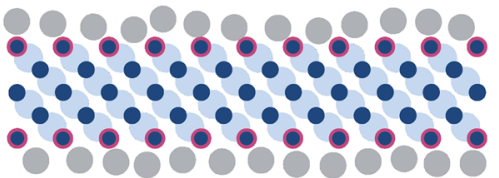

$2 b$

$3 b$

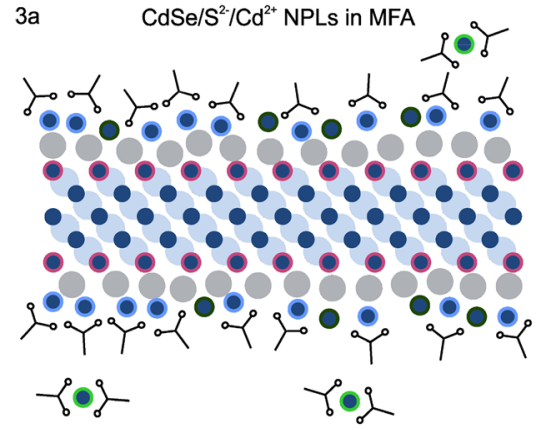

$4 a$

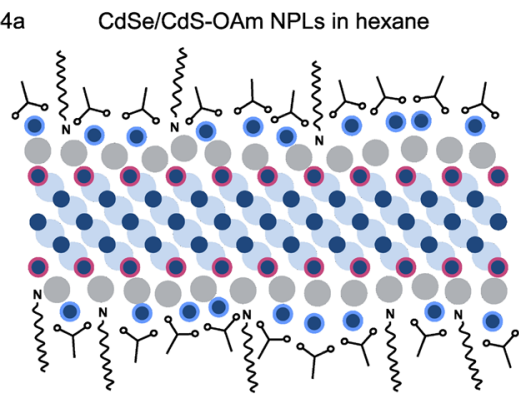

1b
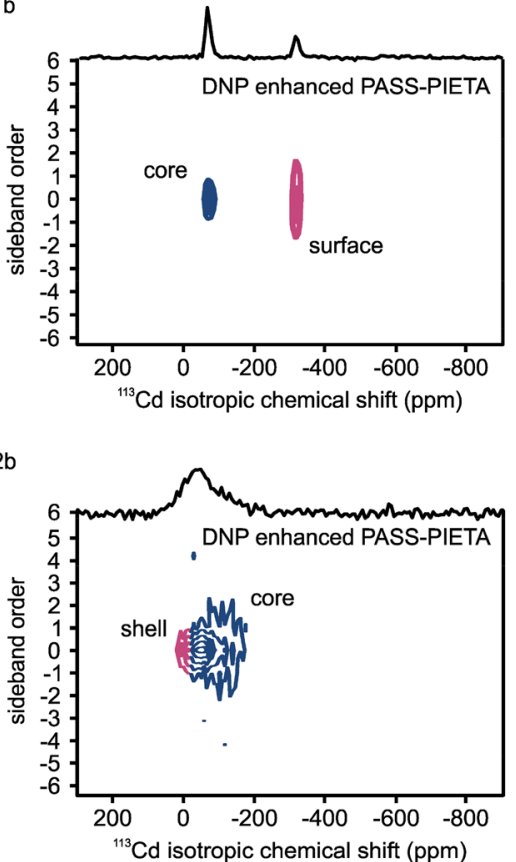

1c
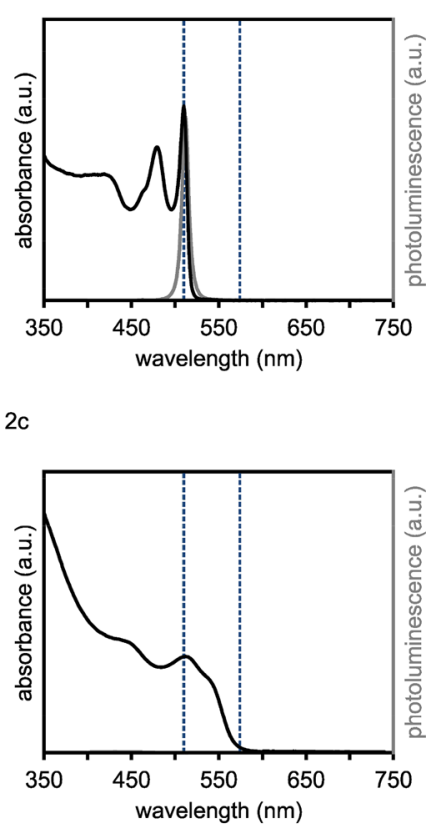

$4 b$
$3 c$

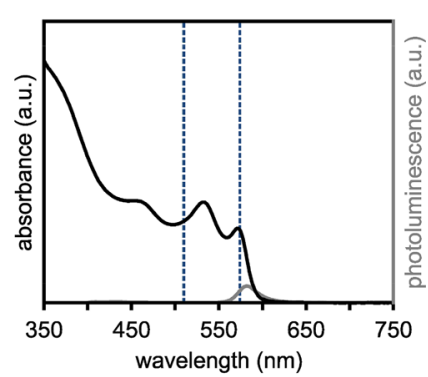

$4 c$
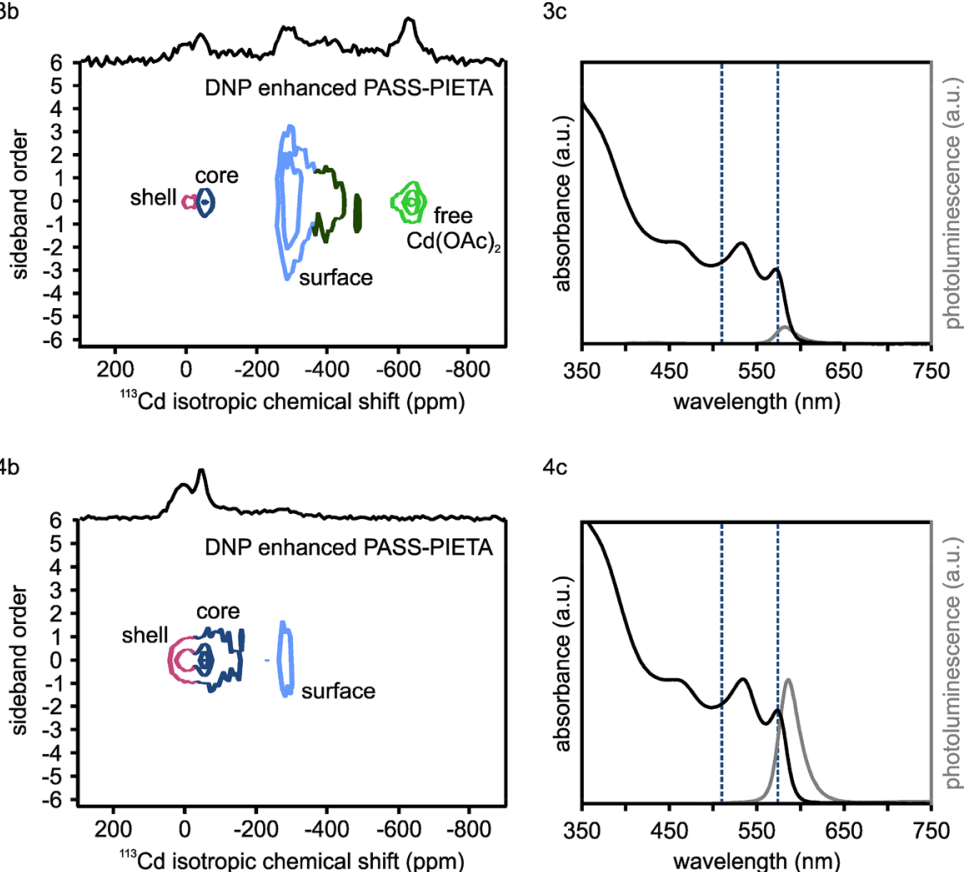

I- acetate Jumm oleate or myristate $\mathrm{N} n \mathrm{~mm}$ oleylamine/oleylammonium $\mathrm{O} O \mathrm{O}$ different Cd species $\mathrm{Se}$

Figure 3. $(1 \mathrm{a}-4 \mathrm{a})$ Schemes of the different steps of the c-ALD growth of one CdS monolayer onto CdSe NPLs, along with the corresponding DNP enhanced PASS-PIETA spectra $(1 \mathrm{~b}-4 \mathrm{~b})$ and optical absorption (black lines) and emission (gray lines) spectra (1c-4c). The color coding of the cadmium atoms in the schemes indicates to which signal they belong to in the corresponding DNP enhanced PASS-PIETA spectrum. The dashed lines in the absorption spectra serve as a guide to the eye by indicating the initial and final excitonic peak position. Panel $1 \mathrm{~b}$ presents the same data as in Figure 1c.

It had been shown that oleate, which was added to the reaction mixture toward the end of the synthesis in the form of oleic acid in order to improve the colloidal stability of the NPLs, and myristate, introduced in the form of cadmium myristate as a $\mathrm{Cd}$ precursor, are the capping ligands in pristine (as-synthesized) ZB CdSe NPLs. ${ }^{164}$ This agrees with the surface cadmium carboxylate signal found at around -311 ppm. Another possible source for carboxylate ligands, which could produce the ${ }^{113} \mathrm{Cd}$ NMR cadmium carboxylate surface signal, is cadmium acetate. This is added to the reaction mixture at elevated temperatures to induce the anisotropic growth of the NCs. ${ }^{12,14,24}$ However, the presence of the surface cadmium acetate could neither be proven nor excluded based on our ${ }^{113} \mathrm{Cd}$ and ${ }^{13} \mathrm{C}$ NMR spectra. The ${ }^{113} \mathrm{Cd}$ NMR signals 
of cadmium oleate, cadmium myristate, and cadmium acetate are most likely overlapping since all carboxylate ligands bidentate, independently of the chain length, as calculated in literature. ${ }^{24,159,163}$ In the ${ }^{13} \mathrm{C}$ NMR spectra of pristine CdSe NPLs in frozen colloidal solutions containing radicals (experimental conditions for DNP), the carboxylate-carbon signals are not resolved. Additionally, the ${ }^{13} \mathrm{C}$ NMR methyl signal of acetate cannot be identified as it overlaps with the ${ }^{13} \mathrm{C}$ NMR signals from the oleate and myristate ligands. Furthermore, methyl signals are difficult to observe with DNP NMR due to their unfavorably fast dynamics. ${ }^{165}$ Therefore, we performed additional ${ }^{2} \mathrm{H}$ NMR experiments to be able to include or exclude the presence of acetate coordinated surface cadmium atoms by comparing NPL samples with natural isotope abundance and with deuteriumenriched cadmium acetate. The results allowed us to conclude that the surface of ZB CdSe NPLs is terminated entirely by the cadmium carboxylate species, with oleate, myristate, and acetate as coordinating ligands (see Figure S2 for more details).

We could not find conclusive evidence for hydroxideterminated surface cadmium, postulated by Bertrand et al. ${ }^{63}$ The presence of such a surface species cannot, however, be excluded based on the present data since its chemical shift is not reported and it might be overlapping with the signal of carboxylate-capped surface cadmium atoms. Nevertheless, such an overlap is rather unlikely since frozen solutions of cadmium carboxylate and cadmium hydroxide have distinctly different chemical shifts (see Figure S3). Although possibly less pronounced, we expect that the difference between the two surface counterparts should also be resolvable based on some DFT calculations we performed on simple cadmium complexes. These indicate that the ${ }^{113} \mathrm{Cd}$ chemical shielding values follow a linear trend upon gradual replacement of oxygen-coordinating ligands with selenium-coordinating ligands at a cadmium atom. We have calculated the chemical shielding of tetrahedral $\left[\mathrm{Cd}\left(\mathrm{OH}_{2}\right)_{4-n}\left(\mathrm{SeH}_{2}\right)_{n}\right]^{2+}$ complexes with $n=0-4$, and the results are shown in Figure 4a. This clear dependency not only justifies the interpolation approach for the exclusion of cadmium hydroxide surface signals but also implies that the directly bound ligands are responsible for the ${ }^{113} \mathrm{Cd}$ chemical shift of cadmium nuclei. This permits us to explain the chemical shift of surface cadmium carboxylate $\left(\delta_{\text {iso }}\left(\mathrm{Cd}(\mathrm{Se})_{2}(\mathrm{COOR})\right)=-311 \mathrm{ppm}\right)$ as it lies almost halfway between the one of core $\mathrm{CdSe}\left(\delta_{\text {iso }}\left(\mathrm{Cd}(\mathrm{Se})_{4}\right)=-62 \mathrm{ppm}\right)$ and free cadmium oleate $\left(\delta_{\text {iso }}\left(\mathrm{Cd}(\text { oleate })_{2}\right)=-694 \mathrm{ppm}\right.$, see Figure S3). Although periodic systems such as solids or slabs of $\mathrm{CdSe}$ would be ideal model systems for DFT calculations (instead of $\left[\mathrm{Cd}\left(\mathrm{XH}_{2}\right)_{4}\right]^{2+}$ complexes), such calculations were not possible because of the present lack of working codes that include spin-orbit coupling (SOC) in the evaluation of NMR chemical shift parameters. In our calculations on $\left[\mathrm{Cd}\left(\mathrm{XH}_{2}\right)_{4}\right]^{2+}$ complexes, SOC was found to be relevant to reproduce the correct trend of chemical shifts, especially for heavier chalcogenide atoms (see the Results and Discussion section further below). Furthermore, it can be noticed that the simple complexes also reproduce well the anisotropy of experimental data, which legitimizes their use as structural analogues in NPLs. For example, the shielding anisotropy of $\left[\mathrm{Cd}\left(\mathrm{OH}_{2}\right)_{2}\left(\mathrm{SeH}_{2}\right)_{2}\right]^{2+}(260 \mathrm{ppm}$, principal values shown in Figure 4) is, within the error, commensurate to $\Delta=-250 \pm$ $20 \mathrm{ppm}$ of the surface cadmium oleate in pristine $\mathrm{ZB} \mathrm{CdSe}$ NPLs (see Table 1).
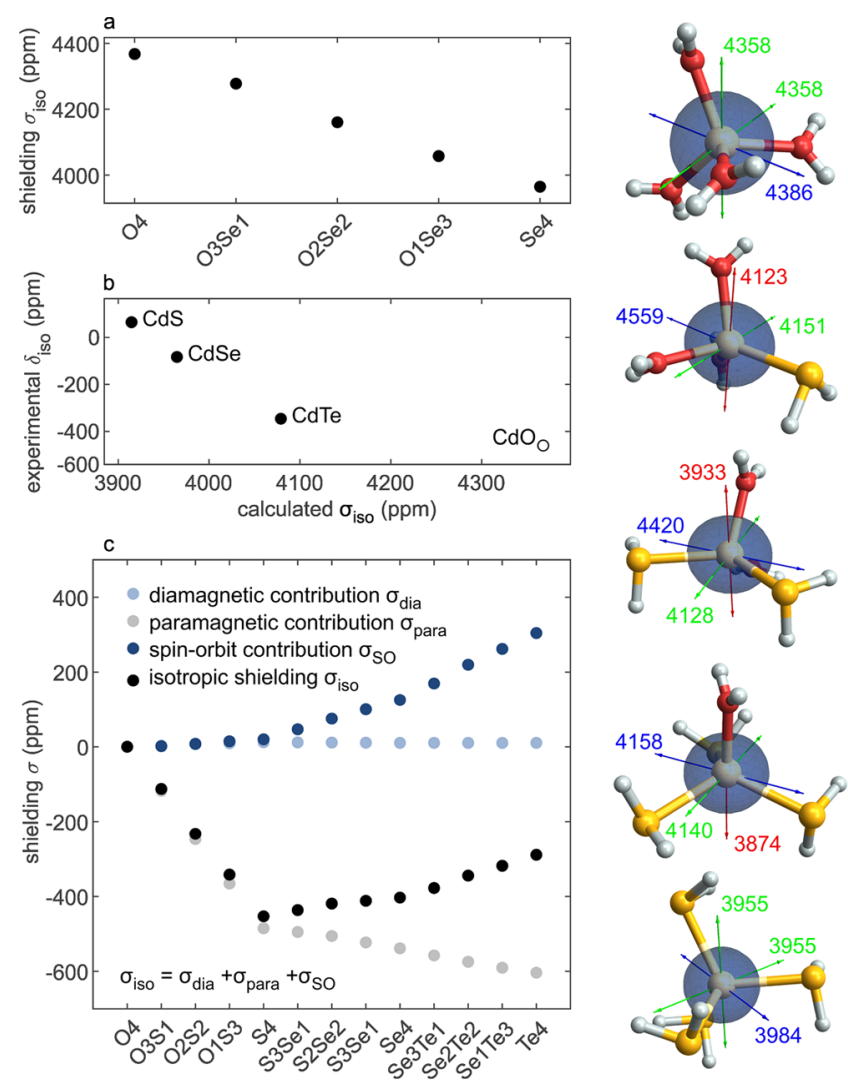

Figure 4. Summary of DFT calculations of the chemical shielding of cadmium in $\left[\mathrm{Cd}\left(\mathrm{XH}_{2}\right)_{4-n}\left(\mathrm{YH}_{2}\right)_{n}\right]^{2+}$ complexes $(\mathrm{X}, \mathrm{Y}=\mathrm{O}, \mathrm{S}, \mathrm{Se}, \mathrm{Te})$. The ligands coordinating to the cadmium atoms are indicated on the $x$-axis, whereby $\mathrm{O}=\mathrm{H}_{2} \mathrm{O}, \mathrm{S}=\mathrm{SH}_{2}, \mathrm{Se}=\mathrm{SeH}_{2}$, and $\mathrm{Te}=\mathrm{TeH}_{2}$. In graph a, the linear behavior of the calculated chemical shielding is illustrated upon a gradual exchange of $\mathrm{H}_{2} \mathrm{O}$ ligands with $\mathrm{SeH}_{2}$. Graph $\mathrm{b}$ shows that the DFT model reproduces the experimentally observed trend for bulk cadmium chalcogenides. We note that CdO crystallizes in a rock-salt structure type (i.e., octahedral coordination) but is calculated in a tetrahedral environment for better comparison. In graph $c$, the different contributions to the chemical shielding of cadmium are plotted individually (light blue, dark blue, and gray circles) as well as their sum (black circles), relative to the shielding of $\left[\mathrm{Cd}\left(\mathrm{OH}_{2}\right)_{4}\right]^{2+}$. Two counteracting contributions are obtained: the paramagnetic (gray circles) and the spin-orbit contributions (dark blue circles). These lead to a turnaround of the isotropic chemical shielding trend, while the diamagnetic contribution (light blue circles) remains very similar for all compounds. Images of the $\left[\mathrm{Cd}\left(\mathrm{OH}_{2}\right)_{4-n}\left(\mathrm{SeH}_{2}\right)_{n}\right]^{2+}(n=0-4)$ complexes ( $\mathrm{H}$ atoms in white, $\mathrm{Cd}$ atoms in gray, $\mathrm{O}$ atoms in red, and $\mathrm{Se}$ atoms in orange) are depicted on the right. The shapes of the ${ }^{113} \mathrm{Cd}$ shielding tensors are shown by the dark spheroids, and the principle axes values and directions are indicated by the blue, green, and red arrows in the order of decreasing shielding.

Sulfide-Capped ZB CdSe/S ${ }^{2-} N P L$ s in MFA. The first step in $c-A L D$ comprises a LE reaction where the long, aliphatic oleate and myristate ligands are replaced by sulfide ligands, thereby transferring the NPLs from an apolar (hexane) to a polar (MFA) phase. This LE has a clear signature in the DNP enhanced PASS-PIETA spectrum of the resulting $\mathrm{CdSe} / \mathrm{S}^{2-}$ NPLs-the surface cadmium carboxylate signal at $-311 \mathrm{ppm}$ vanishes as the sulfide ligands extend the CdSe lattice and terminate the surface of the NPLs. ${ }^{163}$ Now, all of the Cd signal is attributed to the core region (see Figure 3, panel $2 \mathrm{~b}$ ). The maximum intensity of the core signal has shifted to $-52 \mathrm{ppm}$, 
which can be explained by the effect of surface sulfide ions. As mentioned before, DFT calculations on $\left[\mathrm{Cd}\left(\mathrm{XH}_{2}\right)_{4}\right]^{2+}$ indicate a linear behavior when gradually exchanging the kind of chalcogenide ions around cadmium cations. The chemical shift of cadmium coordinating to sulfur and selenium atoms thus approximately corresponds to a weighted linear combination of the pure $\mathrm{CdS}$ and pure CdSe chemical shifts, as can be seen in Figure S4. Since the NPLs are very thin (four CdSe monolayers and one terminating $\mathrm{Cd}$ layer), the sulfide termination causes the ${ }^{113} \mathrm{Cd}$ chemical shift of $\mathrm{CdSe} / \mathrm{S}^{2-}$ NPLs to deviate from pure CdSe, as is evident by the small deshielding effect. The spinning sideband pattern of the signal can be fit by the superposition of two sideband profiles (see Table 1): one without anisotropy and one with a CSA comparable to the one of the cadmium carboxylate signals in oleate-capped CdSe NPLs, most likely from the cadmium atoms in the vicinity of sulfide ligands (pink in Figure 3, panels $2 \mathrm{a}$ and $2 \mathrm{~b}$ ). Moreover, the isotropic chemical shift distribution has significantly increased. This broadening in the isotropic dimension indicates an increased structural disorder within the NPLs. The removal of oleate ligands might have caused distortions of the crystal lattice as well as dislocations of individual atoms. This increases the defectiveness and reduces the crystallinity of not only the surface but of the NPL as a whole. Furthermore, the sulfide ligands might not extend the crystal lattice properly, which also reduces the surface crystallinity.

Overall, the DNP enhanced PASS-PIETA spectrum implies that all organic ligands were exchanged, thus resulting in NPLs whose entire surface is covered by sulfide ligands, yielding an overall negative charge as confirmed by their $\zeta$ potential (see Table S1). The influence of the surface termination on the core cadmium signal manifests itself as deshielding and as an increase in isotropic chemical shift distribution, suggesting that the replacement of ligands disrupts the surface order of the pristine ZB CdSe NPLs.

Core/Shell CdSe/S/Cd NPLs in MFA. The addition of excess cadmium acetate completes the formation of a $\mathrm{CdS}$ monolayer, accompanied by the further shift of the excitonic optical features to the red (Figure 3, panel 3c). In the DNP enhanced PASS-PIETA spectrum, a separation of the core signal into two peaks, one at $12 \mathrm{ppm}$ and one at $-46 \mathrm{ppm}$, is observed. This can be attributed to the completeness of the shell and an improved crystallinity of the NPL core when compared to the sulfide-capped NPLs, hence making these two NC regions spectroscopically more distinct. Based on their isotropic chemical shift values, the following peak assignment can be suggested. The peak at $12 \mathrm{ppm}$ belongs to core cadmium atoms coordinated to sulfur (pink in Figure 3, panels $3 \mathrm{a}$ and $3 \mathrm{~b})$ since bulk CdS $\left(\delta_{\text {iso }}=65 \mathrm{ppm}\right)^{166}$ and spherical CdS NCs $\left(\delta_{\text {iso }}=52 \mathrm{ppm}\right)^{94,98}$ are more deshielded than their selenium counterparts (bulk CdSe $\delta_{\text {iso }}=-83 \mathrm{ppm}^{166}$ and CdSe NCs $\delta_{\text {iso }}$ $=-66 \mathrm{ppm}) .^{94,97,98}$ The peak at $-46 \mathrm{ppm}$ is attributed to cadmium atoms coordinated exclusively to selenium (dark blue signal in Figure 3, panel 3b) since the chemical shift value is close to that of bulk and nanocrystalline CdSe. These nuclei are slightly deshielded compared to pristine CdSe NPLs (-62 ppm). CdSe/CdS core/shell NCs exhibit reduced confinement due to the increased delocalization of the electrons as compared to the initial CdSe NCs. The absolute paramagnetic contribution should, therefore, increase (see a further discussion on the relationship between the chemical shift and the electronic structure in the Supporting Information), resulting in a deshielding of cadmium nuclei in the core/shell NCs versus pristine CdSe NCs. The signal at $-289 \mathrm{ppm}$ is attributed to the surface-terminating cadmium atoms, which are binding to sulfur atoms of the CdS shell on one side and to an acetate ligand on the other. Such deshielding of surface cadmium carboxylate species located on $\mathrm{CdS}$ versus the same species on CdSe had already been reported for spherical cadmium chalcogenide NCs. ${ }^{44}$ The CSA of the cadmium acetate surface species is comparable to that of surface species in pristine CdSe NPLs, although $\eta$ is smaller (Table 1), presumably due to the surface being less flat. The larger magnitude of the anisotropy (Table 1) can be attributed to the increased positional disorder caused by the stronger curvature of the NC surface. Despite a washing step, free $\mathrm{Cd}(\mathrm{OAc})_{2}$ is observed in the DNP enhanced PASS-PIETA spectrum at $-633 \mathrm{ppm}$ (Figure 3, panels 3a and 3b; see also Figure S3 for reference spectra of $\mathrm{Cd}(\mathrm{OAc})_{2}$ in FA, MFA, DNP juice, and $\mathrm{Cd}$ (oleate $)_{2}$ in a TCE-ODE mixture). CP and DNP enhancement efficiencies for this $\mathrm{Cd}$ species might be different from those of NPLs and, hence, produce a much stronger/weaker signal for this impurity compared to its actual concentration within the sample. The excellent solubility of $\mathrm{Cd}(\mathrm{OAc})_{2}$ in MFA could account for the signal of free $\mathrm{Cd}(\mathrm{OAc})_{2}$ in the core/shell $\mathrm{CdSe} / \mathrm{S}^{2-} / \mathrm{Cd}^{2+} \mathrm{NPLs}$ spectrum. By precipitation and redispersion during washing of the NPLs, some of the $\mathrm{Cd}(\mathrm{OAc})^{+}$could be driven away from the surface, according to Le Chatelier's principle. These cations could coordinate to free acetate in solution, where the latter act as counterions for the charged NPLs, which possess a positive $\zeta$ potential of $+5 \mathrm{meV}$ (Table S1). Furthermore, a $\mathrm{Cd}(\mathrm{OAc})^{+}$cation could also remove an acetate ligand from a neighboring cadmium atom when dissolving. As a result, so-called "naked" cadmium atoms would be formed, i.e., cadmium atoms, which are solvated and stabilized by MFA solvent molecules. If such naked surface cadmium species are formed, which is only a hypothesis based on present data, they could be responsible for the signal at $-392 \mathrm{ppm}$, the remaining unassigned signal in the DNP enhanced PASS-PIETA spectrum of core/shell $\mathrm{CdSe} / \mathrm{S}^{2-} /$ $\mathrm{Cd}^{2+}$ NPLs in MFA. The combination of cadmium acetate and naked cadmium as surface species could also explain the slightly positive $\zeta$ potential of the NPLs (Table S1). If the NPLs were completely covered with acetate ligands, they would be neutral in charge and, therefore, colloidally unstable in MFA. Conversely, NPLs without any acetate ligands and hence a completely naked surface would exhibit a larger positive charge than experimentally measured with the $\zeta$ potential (Table S1). We, therefore, hypothesize that the signal at $-392 \mathrm{ppm}$ is engendered by the naked cadmium species. In addition, we cannot exclude the incomplete shell formation, leading to the exposure of sulfide at the surface, cadmium from lower layers, or even selenide at the surface, thus explaining the dramatic increase of the isotropic distribution of the surface species compared to the initial CdSe NPLs.

Oleylamine-Capped Core/Shell CdSe/CdS NPLs in Hexane. After the precipitation, the core/shell NPLs are dispersed in hexane containing 12 vol \% of OAm (instead of being solubilized again in MFA), and the DNP enhanced PASSPIETA spectrum is collected (Figure 3, subpanel $4 \mathrm{~b}$ ). The isotropic chemical shift distribution is reduced, and the NMR signals are narrower and better defined than in the case of $\mathrm{CdSe} / \mathrm{S}^{2-}$ or $\mathrm{CdSe} / \mathrm{S}^{2-} / \mathrm{Cd}^{2+} \mathrm{NPLs}$ in MFA. This points to a less disordered structure. However, these NPLs do not attain the same degree of crystallinity as the pristine CdSe NPLs. The 
signals of core $\mathrm{CdSe}$ and core cadmium atoms coordinated to sulfur are still present at -41 and $18 \mathrm{ppm}$, respectively, but the signals from the free $\mathrm{Cd}(\mathrm{OAc})_{2}$ as well as the signal at -392 ppm are no longer observed. Only a signal at $-261 \mathrm{ppm}$ remained, which we tentatively attribute to carboxylate-bound surface cadmium, which must be bound to acetate since oleate was not carried along during the synthesis steps in MFA. Substantial coverage of the surface cadmium atoms by oleylamine is rather implausible for reasons of charge balance of the overall NPLs. Alternatively, there might also be other surface cadmium species coordinating to oxygen atoms, e.g., hydroxide ligands. There is no evidence for the presence of carbamate ligands, which could have formed by the reaction of carbon dioxide from the air and OAm because there is no ${ }^{13} \mathrm{C}$ NMR signal in the characteristic chemical shift regions for carbamates around $160 \mathrm{ppm}$, neither in solution nor in DNP NMR (Figures S5 and S6).

There are two plausible scenarios for the fate of the naked cadmium during the transfer of the core/shell NPLs from MFA to hexane: either acetate, which was acting as a counterion to the $\mathrm{CdSe} / \mathrm{S}^{2-} / \mathrm{Cd}^{2+} \mathrm{NPLs}$ in MFA coordinates to the previously solvated surface cadmium atoms, or the solvated surface cadmium atoms are stripped-off during purification of the CdSe/CdS-OAm NPLs. One can conclude that there must be OAm coordinating to the surface, based on previous assignments and that OAm is found in the ${ }^{13} \mathrm{C}$ DNP NMR spectrum of the CdSe/CdS-OAm NPLs (see Figure S6). This conclusion is further supported by the fact that acetate (or hydroxide) ligands are by themselves incapable of colloidally stabilizing the NPLs in both hexane and TCE, but since the only observed ${ }^{113} \mathrm{Cd}$ NMR at $-261 \mathrm{ppm}$ was attributed to the surface cadmium acetate, the OAm must be coordinating to sulfur exposed at the surface. Presumably, OAm also displaces some of the cadmium atoms, similar to how it has been already reported for butylamine on pristine NPLs. ${ }^{164}$ This increases the colloidal stability of the NPLs by augmenting the number of coordinating ligands with long, aliphatic tails. Our findings explain the improved colloidal stability of OAm-capped core/ shell CdSe/CdS NPLs in hexane versus core/shell CdSe/CdS NPLs in MFA by demonstrating that sulfur sites are passivated by OAm. Such surface passivation also explains the observation of increased PL intensities (see Figure 3, panels 1c-4c) as also reported in literature. ${ }^{39}$

On the basis of these studies, we conclude that NMR spectra can both trace the molecular evolution of the NPL surface in response to various experimental procedures during the c-ALD and serve as a sensitive probe of the change in the atomic disorder. For instance, the flat surface and the high crystallinity of the sample are largely compromised during the CdS shell growth by c-ALD, as is evidenced by the inhomogeneously broadened signals in the DNP enhanced PASS-PIETA spectrum (Figure 3 ). If the $\mathrm{CdS}$ shell had been a perfect epitaxial extension of the underlying $\mathrm{CdSe}$ lattice, a comparable signal width in the isotropic dimension should have been maintained after the final step of c-ALD (Figure 3, panels $4 \mathrm{a}-4 \mathrm{c}$ ).

DFT Calculations Explain the Trend of CdO, CdS, CdSe, and CdTe Bulk Chemical Shifts. The fact that the first coordination sphere is the most important structural factor determining the ${ }^{113} \mathrm{Cd}$ shielding has proven very useful for the signal assignment in the previous sections. The simple cadmium complexes of the type $\left[\mathrm{Cd}\left(\mathrm{XH}_{2}\right)_{4}\right]^{2+}(\mathrm{X}=\mathrm{O}, \mathrm{S}$, $\mathrm{Se}, \mathrm{Te})$, which we have used so far for our DFT calculations, also offer the possibility to shed light onto the deshielding trend in bulk chalcogenides chemical shifts from $\mathrm{CdO}$ $(-460),{ }^{167}$ to $\mathrm{CdTe}(-346 \mathrm{ppm}),{ }^{166} \mathrm{CdSe}(-83 \mathrm{ppm}),{ }^{166}$ and finally CdS $(65 \mathrm{ppm}) .{ }^{166}$ This trend is surprising because it does not follow the sequence down the group VIA in the periodic table: $\mathrm{O}, \mathrm{S}, \mathrm{Se}, \mathrm{Te}$. Note that the the total ${ }^{113} \mathrm{Cd}$ shielding, as well as the diamagnetic, paramagnetic, and spinorbit contributions of an octahedral $\left[\mathrm{Cd}\left(\mathrm{OH}_{2}\right)_{6}\right]^{2+}$ complex, which is more closely related to the rock-salt crystal structure of bulk $\mathrm{CdO}$, give similar but not identical results as for tetrahedral $\left[\mathrm{Cd}\left(\mathrm{OH}_{2}\right)_{4}\right]^{2+}$ (Table S2) as the charge from cadmium is distributed on a different number of ligands, which results in significantly different bond lengths. The latter coordination symmetry is reminiscent of the tetrahedral bonding in ZB and wurtzite crystal structures of bulk CdTe, $\mathrm{CdSe}$, and CdS. We, therefore, restrained our DFT calculations to tetrahedral cadmium complexes. These simple model systems $\left[\mathrm{Cd}\left(\mathrm{XH}_{2}\right)_{4}\right]^{2+}(\mathrm{X}=\mathrm{O}, \mathrm{S}, \mathrm{Se}, \mathrm{Te})$ reproduce the trend observed for the bulk materials, predicting the highest shielding for $\mathrm{CdO}$, followed by $\mathrm{CdTe}$, CdSe, and $\mathrm{CdS}$ (Figure $4 \mathrm{~b}$ ). It should be noted that the value of a cubic, rock-salt structured $\mathrm{CdO}$ with 6-fold coordination of the cadmium had to be used as an experimental isotropic chemical shift for CdO. These results suggest that also the ${ }^{113} \mathrm{Cd}$ bulk chemical shifts of $\mathrm{CdO}, \mathrm{CdS}, \mathrm{CdSe}$, and CdTe are mainly due to the immediate coordination environment of the cadmium atom, rather than due to long-range, bulk properties.

In order to further delineate this trend, we decomposed the calculated shielding of all possible combinations within the formula $\left[\mathrm{Cd}\left(\mathrm{XH}_{2}\right)_{4-n}\left(\mathrm{YH}_{2}\right)_{n}\right]^{2+}(\mathrm{X}, \mathrm{Y}=\mathrm{O}, \mathrm{S}, \mathrm{Se}, \mathrm{Te})$ into diamagnetic, paramagnetic, and spin-orbit contributions (not to be confused with the bulk properties diamagnetism and paramagnetism). ${ }^{168-170}$ The diamagnetic contributions arise from a molecule's electronic ground state and generally shield the nucleus. They are mostly affected by core orbitals and hence are rather independent of a nucleus' chemical environment. The paramagnetic contributions, on the other hand, arise from the admixture of electronically excited states to the ground state, mostly arising from frontier molecular orbitals close in energy. This interaction leads to the generation of deshielding paramagnetic currents (for a more detailed description, see the Relation of the Chemical Shift and the Electronic Structure section in the Supporting Information). Finally, for systems containing heavy atoms, the occurrence of SOC can act as an additional contribution to the chemical shielding and significantly influences the observed chemical shift. Depending on the exact bonding situation and electronic structure, these contributions can either shield or deshield a nucleus. ${ }^{171,172}$ In the case of the investigated cadmium systems, with a $\mathrm{d}^{10}$ electron configuration, spin-orbit effects are expected to shield the nucleus.

The results of this decomposition for a selected series of compounds are shown in Figure 4c (complete results are given in Table S3 and Table S4). The diamagnetic contributions were indeed found to be roughly equal for all investigated compounds (they give rise to shielding in the range of 4819$4830 \mathrm{ppm}$ ). The paramagnetic contributions are deshielding. Upon going from an oxygen environment in $\left[\mathrm{Cd}\left(\mathrm{OH}_{2}\right)_{4}\right]^{2+}$ to $\left[\mathrm{Cd}\left(\mathrm{TeH}_{2}\right)_{4}\right]^{2+}$, the shielding that originates from these contributions decreases from $-992 \mathrm{ppm}$ to $-1596 \mathrm{ppm}$ in a fairly continuous way for all intermediate compounds. Simultaneously, the shielding contributions originating from spin-orbit interactions increase from 541 to $846 \mathrm{ppm}$. 
To summarize, the trend in total shielding for $\left[\mathrm{Cd}\left(\mathrm{XH}_{2}\right)_{4}\right]^{2+}$ systems is affected by two opposing trends: a deshielding paramagnetic contribution, which increases in magnitude as $\mathrm{X}$ atoms get heavier, and a shielding spin-orbit contribution, which increases along the same line. The increase in paramagnetic deshielding is most pronounced for oxygenand sulfur-based ligands, whereas the change in spin-orbit contributions is much more pronounced from $\mathrm{S}$ to Se and Te in the coordination sphere of cadmium. Usually, paramagnetic deshielding is associated with the coupling of high-lying occupied and low-lying vacant orbitals (see the Relation of the Chemical Shift and the Electronic Structure section in the Supporting Information). In a $\mathrm{Cd}^{2+}$ ion with a $\mathrm{d}^{10}$ electron configuration, no low-lying vacant orbitals are expected, yet the interaction of the cadmium atoms with ligands introduces vacant orbitals (i.e., $\sigma^{*}$ orbitals of the Cd-ligand bond) with contributions on the cadmium, hence allowing for paramagnetic deshielding. This effect is more pronounced for stronger interactions between the $\mathrm{Cd}$ and less electronegative $\mathrm{X}$ atoms. Therefore, only a weak perturbation of the electronic structure of the $\mathrm{Cd}^{2+}$ center in $\left[\mathrm{Cd}\left(\mathrm{OH}_{2}\right)_{4}\right]^{2+}$ is observed in the form of a weak paramagnetic deshielding since the interaction of cadmium and oxygen is rather ionic. With increasing ligand weight, the metal-ligand interaction becomes less ionic, and the energy difference between filled and vacant molecular orbitals decreases. This translates into a decrease of the band gap with increasing ligand weight and into an increased paramagnetic deshielding contribution (see the Relation of the Chemical Shift and the Electronic Structure section in the Supporting Information).

While periodic DFT calculations would provide more accurate model structures for bulk materials and NPLs, to the best of our knowledge, no existing code takes SOC into consideration for the evaluation of chemical shielding. Therefore, currently, periodic calculations have not been used to understand the experimental trends of the ${ }^{113} \mathrm{Cd}$ chemical shift values in cadmium chalcogenide compounds. In conclusion, using advanced NMR spectroscopy, we have gained insight into the surface chemistry of pristine ZB CdSe NPLs and CdSe/CdS core/shell NPLs prepared by c-ALD. We have shown that as-synthesized ZB CdSe NPLs are not only capped by oleate and myristate ligands but also by acetate ligands. We have then corroborated the expected mechanism of the CdS shell growth by c-ALD onto ZB CdSe NPLs, by assigning the observed NMR signals to atomic or molecular species in the core, shell, and at the surface of the NPLs, as well as in a solution. Throughout the low-temperature CdS shell growth by c-ALD, the high order and atomically well-defined surfaces of pristine ZB CdSe NPLs become rougher, more defective, and more disordered, as reflected in the increased isotropic chemical shift distribution in the DNP enhanced PASS-PIETA spectra. With every step of c-ALD, NMR indicated an increase in disorder, except for the last step where some order was recovered, though not to the extent observed for the pristine ZB CdSe NPLs.

DFT calculations helped to rationalize a nonmonotonic trend of chemical shifts for bulk materials: shielding increases in the series $\mathrm{CdS}, \mathrm{CdSe}, \mathrm{CdTe}$, and $\mathrm{CdO}$. The contributions of SOC and paramagnetic contributions to the chemical shielding counteract one another and vary in weight for the different cadmium chalcogenide compounds. Furthermore, the results from DFT calculations on model molecular mixed-chalcogenide $\mathrm{Cd}$ complexes explain the observed evolution of the $\mathrm{Cd}$
NPL core and surface signals upon addition of the CdS shell or binding to carboxylates (e.g., mixed $\mathrm{S}-\mathrm{Se}, \mathrm{Se}-\mathrm{O}$, or $\mathrm{S}-\mathrm{O}$ coordination).

In this work, the application of NMR spectroscopy as a characterization method for colloidal semiconductor NCs has been instrumental for reinforcing the atomistic and molecular understanding of these materials' surface and core structure under different surface manipulations. The results obtained on a rather canonical system of $\mathrm{CdSe}$ nanostructures are important in several regards. They show the utility of the DNP enhanced NMR methods for tracing the chemical processes involving colloidal nanomaterials with minimal sample-altering manipulations. The methodology allows for a speedy collection of the desired information, e.g., with needed resolution and high sensitivity, at mg-scale quantities of the analytes. PASS-PIETA NMR spectroscopy has greatly expanded the accuracy of the assignment of multiple signals inherently present in complex nanomaterials.

\section{ASSOCIATED CONTENT}

\section{Supporting Information}

The Supporting Information is available free of charge at https://pubs.acs.org/doi/10.1021/acs.nanolett.9b04870.

Materials, methods, characterization, relation of the chemical shift and electronic structure, TEM images, NMR spectra, sideband pattern fit to extract CSA parameters, and NMR experiments (PDF)

\section{AUTHOR INFORMATION}

\section{Corresponding Authors}

Christophe Copéret - Department of Chemistry and Applied Biosciences, ETH Zürich, Zurich CH-8093, Switzerland; ○ orcid.org/0000-0001-9660-3890; Email: ccoperet@ ethz.ch

Maksym V. Kovalenko - Department of Chemistry and Applied Biosciences, ETH Zürich, Zurich CH-8093, Switzerland; Empa-Swiss Federal Laboratories for Materials Science and Technology, Zurich CH-8600, Switzerland; ○ orcid.org/0000-0002-6396-8938; Email: mvkovalenko@ ethz.ch

\section{Authors}

Laura Piveteau - Department of Chemistry and Applied Biosciences, ETH Zürich, Zurich CH-8093, Switzerland; EmpaSwiss Federal Laboratories for Materials Science and Technology, Zurich CH-8600, Switzerland

Dmitry N. Dirin - Department of Chemistry and Applied Biosciences, ETH Zürich, Zurich CH-8093, Switzerland; EmpaSwiss Federal Laboratories for Materials Science and Technology, Zurich CH-8600, Switzerland

Christopher P. Gordon - Department of Chemistry and Applied Biosciences, ETH Zürich, Zurich CH-8093, Switzerland; o orcid.org/0000-0002-2199-8995

Brennan J. Walder - Institut des Sciences et Ingénierie Chimiques, Ecole Polytechnique Féderale de Lausanne (EPFL), 1015 Lausanne, Switzerland

Ta-Chung Ong - Department of Chemistry and Applied Biosciences, ETH Zürich, Zurich CH-8093, Switzerland

Lyndon Emsley - Institut des Sciences et Ingénierie Chimiques, Ecole Polytechnique Féderale de Lausanne (EPFL), 1015 Lausanne, Switzerland; 이이.org/0000-0003-1360-2572

Complete contact information is available at: 
https://pubs.acs.org/10.1021/acs.nanolett.9b04870

\section{Author Contributions}

D.N.D. synthesized all NPLs, L.P formulated all samples for DNP NMR; L.P. and T.C.O. carried out DNP NMR measurements. L.P., T.C.O., B.J.W., and L.E. analyzed the DNP NMR data; C.P.G. performed all DFT calculations, and M.K. and C.C. conceived and supervised the project. The manuscript was prepared and written through the contribution of all authors. All authors have given approval to the final version of the manuscript.

\section{Notes}

The authors declare no competing financial interest.

\section{ACKNOWLEDGMENTS}

M.K. acknowledges financial support from the European Union through the FP7 (ERC Starting Grant NANOSOLID, GA 306733) and through the Horizon 2020 research and innovation program ([819740], ERC project SCALE-HALO). L.E. acknowledges support from the ERC Advanced Grant (320860), and L.P, and C.P.G. acknowledge financial support from the Scholarship Fond of the Swiss Chemical Industry (SSCI Award 2015 and 2017). René Verel is acknowledged for his help at the NMR facility at ETH Zurich. The Scope M (ETH Zürich), Electron Microscopy Center at Empa, and Maryna Bodnarchuk are acknowledged for taking TEM pictures. We thank Y. Kelestemur for discussions and for reading the manuscript.

\section{REFERENCES}

(1) Kovalenko, M. V.; Manna, L.; Cabot, A.; Hens, Z.; Talapin, D. V.; Kagan, C. R.; Klimov, V. I.; Rogach, A. L.; Reiss, P.; Milliron, D. J.; Guyot-Sionnnest, P.; Konstantatos, G.; Parak, W. J.; Hyeon, T.; Korgel, B. A.; Murray, C. B.; Heiss, W. Prospects of Nanoscience with Nanocrystals. ACS Nano 2015, 9 (2), 1012-1057.

(2) Pietryga, J. M.; Park, Y.-S.; Lim, J.; Fidler, A. F.; Bae, W. K.; Brovelli, S.; Klimov, V. I. Spectroscopic and Device Aspects of Nanocrystal Quantum Dots. Chem. Rev. 2016, 116 (18), 1051310622.

(3) Talapin, D. V.; Lee, J.-S.; Kovalenko, M. V.; Shevchenko, E. V. Prospects of Colloidal Nanocrystals for Electronic and Optoelectronic Applications. Chem. Rev. 2010, 110 (1), 389-458.

(4) Murray, C. B.; Norris, D. J.; Bawendi, M. G. Synthesis and Characterization of Nearly Monodisperse CdE (E = Sulfur, Selenium, Tellurium) Semiconductor Nanocrystallites. J. Am. Chem. Soc. 1993, 115 (19), 8706-8715.

(5) Manna, L.; Scher, E. C.; Alivisatos, A. P. Synthesis of Soluble and Processable Rod-, Arrow-, Teardrop-, and Tetrapod-Shaped CdSe Nanocrystals. J. Am. Chem. Soc. 2000, 122 (51), 12700-12706.

(6) Yin, Y.; Alivisatos, A. P. Colloidal Nanocrystal Synthesis and the Organic-Inorganic Interface. Nature 2005, 437, 664-670.

(7) Peng, Z. A.; Peng, X. Formation of High-Quality CdTe, CdSe, and $\mathrm{CdS}$ Nanocrystals Using $\mathrm{CdO}$ as Precursor. J. Am. Chem. Soc. 2001, 123 (1), 183-184.

(8) Liu, Z.; Ma, W.; Ye, X.; Wu, N.; Lee, D.; Striolo, A. Chapter 2 Shape Control in the Synthesis of Colloidal Semiconductor Nanocrystals. Anisotropic Particle Assemblies 2018, 37-54.

(9) Murray, C. B.; Kagan, C. R.; Bawendi, M. G. Synthesis and Characterization of Monodisperse Nanocrystals and Close-Packed Nanocrystal Assemblies. Annu. Rev. Mater. Sci. 2000, 30 (1), 545610.

(10) Peng, X.; Manna, L.; Yang, W.; Wickham, J.; Scher, E.; Kadavanich, A.; Alivisatos, A. P. Shape Control of CdSe Nanocrystals. Nature 2000, 404, 59-61.

(11) Lhuillier, E.; Pedetti, S.; Ithurria, S.; Nadal, B.; Heuclin, H.; Dubertret, B. Two-Dimensional Colloidal Metal Chalcogenides
Semiconductors: Synthesis, Spectroscopy, and Applications. Acc. Chem. Res. 2015, 48 (1), 22-30.

(12) Ithurria, S.; Dubertret, B. Quasi 2D Colloidal CdSe Platelets with Thicknesses Controlled at the Atomic Level. J. Am. Chem. Soc. 2008, 130 (49), 16504-16505.

(13) She, C.; Fedin, I.; Dolzhnikov, D. S.; Demortière, A.; Schaller, R. D.; Pelton, M.; Talapin, D. V. Low-Threshold Stimulated Emission Using Colloidal Quantum Wells. Nano Lett. 2014, 14 (5), 27722777.

(14) Ithurria, S.; Tessier, M. D.; Mahler, B.; Lobo, R. P. S. M.; Dubertret, B.; Efros, A. L. Colloidal Nanoplatelets with TwoDimensional Electronic Structure. Nat. Mater. 2011, 10, 936-941.

(15) Prudnikau, A.; Chuvilin, A.; Artemyev, M. CdSe-CdS Nanoheteroplatelets with Efficient Photoexcitation of Central CdSe Region through Epitaxially Grown CdS Wings. J. Am. Chem. Soc. 2013, 135 (39), 14476-14479.

(16) Rossinelli, A. A.; Riedinger, A.; Marqués-Gallego, P.; Knüsel, P. N.; Antolinez, F. V.; Norris, D. J. High-Temperature Growth of Thick-Shell CdSe/CdS Core/Shell Nanoplatelets. Chem. Commun. 2017, 53 (71), 9938-9941.

(17) Fan, F.; Kanjanaboos, P.; Saravanapavanantham, M.; Beauregard, E.; Ingram, G.; Yassitepe, E.; Adachi, M. M.; Voznyy, O.; Johnston, A. K.; Walters, G.; Kim, G.-H.; Lu, Z.-H.; Sargent, E. H. Colloidal CdSe $e_{1-x} S_{x}$ Nanoplatelets with Narrow and ContinuouslyTunable Electroluminescence. Nano Lett. 2015, 15 (7), 4611-4615.

(18) Kelestemur, Y.; Dede, D.; Gungor, K.; Usanmaz, C. F.; Erdem, O.; Demir, H. V. Alloyed Heterostructures of $\mathrm{CdSe}_{\mathrm{x}} \mathrm{S}_{1-\mathrm{x}}$ Nanoplatelets with Highly Tunable Optical Gain Performance. Chem. Mater. 2017, 29 (11), 4857-4865.

(19) Vasiliev, R. B.; Lazareva, E. P.; Karlova, D. A.; Garshev, A. V.; Yao, Y.; Kuroda, T.; Gaskov, A. M.; Sakoda, K. Spontaneous Folding of CdTe Nanosheets Induced by Ligand Exchange. Chem. Mater. 2018, 30 (5), 1710-1717.

(20) Schlenskaya, N. N.; Yao, Y.; Mano, T.; Kuroda, T.; Garshev, A. V.; Kozlovskii, V. F.; Gaskov, A. M.; Vasiliev, R. B.; Sakoda, K. Scrolllike Alloyed $\mathrm{CdS}_{\mathrm{x}} \mathrm{Se}_{1-\mathrm{x}}$ Nanoplatelets: Facile Synthesis and Detailed Analysis of Tunable Optical Properties. Chem. Mater. 2017, 29 (2), $579-586$.

(21) Diroll, B. T.; Cho, W.; Coropceanu, I.; Harvey, S. M.; Brumberg, A.; Holtgrewe, N.; Crooker, S. A.; Wasielewski, M. R.; Prakapenka, V. B.; Talapin, D. V.; Schaller, R. D. Semiconductor Nanoplatelet Excimers. Nano Lett. 2018, 18, 6948.

(22) Cho, W.; Kim, S.; Coropceanu, I.; Srivastava, V.; Diroll, B. T.; Hazarika, A.; Fedin, I.; Galli, G.; Schaller, R. D.; Talapin, D. V. Direct Synthesis of Six-Monolayer $(1.9 \mathrm{~nm})$ Thick Zinc-Blende CdSe Nanoplatelets Emitting at $585 \mathrm{~nm}$. Chem. Mater. 2018, 30 (20), 6957-6960.

(23) Ott, F. D.; Riedinger, A.; Ochsenbein, D. R.; Knüsel, P. N.; Erwin, S. C.; Mazzotti, M.; Norris, D. J. Ripening of Semiconductor Nanoplatelets. Nano Lett. 2017, 17 (11), 6870-6877.

(24) Riedinger, A.; Ott, F. D.; Mule, A.; Mazzotti, S.; Knusel, P. N.; Kress, S. J. P.; Prins, F.; Erwin, S. C.; Norris, D. J. An Intrinsic Growth Instability in Isotropic Materials Leads to Quasi-Two-Dimensional Nanoplatelets. Nat. Mater. 2017, 16, 743-748.

(25) Tessier, M. D.; Spinicelli, P.; Dupont, D.; Patriarche, G.; Ithurria, S.; Dubertret, B. Efficient Exciton Concentrators Built from Colloidal Core/Crown CdSe/CdS Semiconductor Nanoplatelets. Nano Lett. 2014, 14 (1), 207-213.

(26) Mahler, B.; Nadal, B.; Bouet, C.; Patriarche, G.; Dubertret, B. Core/Shell Colloidal Semiconductor Nanoplatelets. J. Am. Chem. Soc. 2012, 134 (45), 18591-18598.

(27) Hazarika, A.; Fedin, I.; Hong, L.; Guo, J.; Srivastava, V.; Cho, W.; Coropceanu, I.; Portner, J.; Diroll, B. T.; Philbin, J. P.; Rabani, E.; Klie, R.; Talapin, D. V. Colloidal Atomic Layer Deposition with Stationary Reactant Phases Enables Precise Synthesis of "Digital" IIVI Nano-heterostructures with Exquisite Control of Confinement and Strain. J. Am. Chem. Soc. 2019, 141 (34), 13487-13496.

(28) She, C.; Fedin, I.; Dolzhnikov, D. S.; Dahlberg, P. D.; Engel, G. S.; Schaller, R. D.; Talapin, D. V. Red, Yellow, Green, and Blue 
Amplified Spontaneous Emission and Lasing Using Colloidal CdSe Nanoplatelets. ACS Nano 2015, 9 (10), 9475-9485.

(29) Kelestemur, Y.; Guzelturk, B.; Erdem, O.; Olutas, M.; Gungor, K.; Demir, H. V. Platelet-in-Box Colloidal Quantum Wells: CdSe/ CdS@CdS Core/Crown@Shell Heteronanoplatelets. Adv. Funct. Mater. 2016, 26 (21), 3570-3579.

(30) Tessier, M. D.; Javaux, C.; Maksimovic, I.; Loriette, V.; Dubertret, B. Spectroscopy of Single CdSe Nanoplatelets. ACS Nano 2012, 6 (8), 6751-6758.

(31) Nasilowski, M.; Mahler, B.; Lhuillier, E.; Ithurria, S.; Dubertret, B. Two-Dimensional Colloidal Nanocrystals. Chem. Rev. 2016, 116 (18), 10934-10982.

(32) Achtstein, A. W.; Schliwa, A.; Prudnikau, A.; Hardzei, M.; Artemyev, M. V.; Thomsen, C.; Woggon, U. Electronic Structure and Exciton-Phonon Interaction in Two-Dimensional Colloidal CdSe Nanosheets. Nano Lett. 2012, 12 (6), 3151-3157.

(33) Pelton, M. Carrier Dynamics, Optical Gain, and Lasing with Colloidal Quantum Wells. J. Phys. Chem. C 2018, 122 (20), 1065910674.

(34) Olutas, M.; Guzelturk, B.; Kelestemur, Y.; Yeltik, A.; Delikanli, S.; Demir, H. V. Lateral Size-Dependent Spontaneous and Stimulated Emission Properties in Colloidal CdSe Nanoplatelets. ACS Nano 2015, 9 (5), 5041-5050.

(35) Yeltik, A.; Delikanli, S.; Olutas, M.; Kelestemur, Y.; Guzelturk, B.; Demir, H. V. Experimental Determination of the Absorption Cross-Section and Molar Extinction Coefficient of Colloidal CdSe Nanoplatelets. J. Phys. Chem. C 2015, 119 (47), 26768-26775.

(36) Guzelturk, B.; Pelton, M.; Olutas, M.; Demir, H. V. Giant Modal Gain Coefficients in Colloidal II-VI Nanoplatelets. Nano Lett. 2019, 19 (1), 277-282.

(37) Christodoulou, S.; Climente, J. I.; Planelles, J.; Brescia, R.; Prato, M.; Martín-García, B.; Khan, A. H.; Moreels, I. ChlorideInduced Thickness Control in CdSe Nanoplatelets. Nano Lett. 2018, 18,6248 .

(38) Tessier, M. D.; Mahler, B.; Nadal, B.; Heuclin, H.; Pedetti, S.; Dubertret, B. Spectroscopy of Colloidal Semiconductor Core/Shell Nanoplatelets with High Quantum Yield. Nano Lett. 2013, 13 (7), 3321-3328.

(39) Yadav, S.; Singh, A.; Thulasidharan, L.; Sapra, S. Surface Decides the Photoluminescence of Colloidal CdSe Nanoplatelets Based Core/Shell Heterostructures. J. Phys. Chem. C 2018, 122 (1), 820-829.

(40) Polovitsyn, A.; Dang, Z.; Movilla, J. L.; Martín-García, B.; Khan, A. H.; Bertrand, G. H. V.; Brescia, R.; Moreels, I. Synthesis of AirStable CdSe/ZnS Core-Shell Nanoplatelets with Tunable Emission Wavelength. Chem. Mater. 2017, 29 (13), 5671-5680.

(41) Altintas, Y.; Quliyeva, U.; Gungor, K.; Erdem, O.; Kelestemur, Y.; Mutlugun, E.; Kovalenko, M. V.; Demir, H. V. Highly Stable, Near-Unity Efficiency Atomically Flat Semiconductor Nanocrystals of $\mathrm{CdSe} / \mathrm{ZnS}$ Hetero-Nanoplatelets Enabled by ZnS-Shell Hot-Injection Growth. Small 2019, 15 (8), 1804854.

(42) Rossinelli, A. A.; Rojo, H.; Mule, A. S.; Aellen, M.; Cocina, A.; De Leo, E.; Schäublin, R.; Norris, D. J. High-Temperature Synthesis of CdSe-Based Core/Shell, Core/Shell/Shell, and Core/Graded-Shell Nanoplatelets for Stable and Efficient Narrowband Emitters. ArXiv eprints 2019.

(43) Shendre, S.; Delikanli, S.; Li, M.; Dede, D.; Pan, Z.; Ha, S. T.; Fu, Y. H.; Hernández-Martínez, P. L.; Yu, J.; Erdem, O.; Kuznetsov, A. I.; Dang, C.; Sum, T. C.; Demir, H. V. Ultrahigh-Efficiency Aqueous Flat Nanocrystals of CdSe/CdS@Cd $\mathrm{Cd}_{1-\mathrm{x}} \mathrm{Zn}_{\mathrm{x}} \mathrm{S}$ Colloidal Core/ Crown@Alloyed-Shell Quantum Wells. Nanoscale 2019, 11 (1), 301310.

(44) Pedetti, S.; Ithurria, S.; Heuclin, H.; Patriarche, G.; Dubertret, B. Type-II CdSe/CdTe Core/Crown Semiconductor Nanoplatelets. J. Am. Chem. Soc. 2014, 136 (46), 16430-16438.

(45) Delikanli, S.; Guzelturk, B.; Hernández-Martínez, P. L.; Erdem, T.; Kelestemur, Y.; Olutas, M.; Akgul, M. Z.; Demir, H. V. Continuously Tunable Emission in Inverted Type-I CdS/CdSe
Core/Crown Semiconductor Nanoplatelets. Adv. Funct. Mater. 2015, 25 (27), 4282-4289.

(46) Dufour, M.; Steinmetz, V.; Izquierdo, E.; Pons, T.; Lequeux, N.; Lhuillier, E.; Legrand, L.; Chamarro, M.; Barisien, T.; Ithurria, S. Engineering Bicolor Emission in 2D Core/Crown CdSe/CdSe ${ }_{1-x} \mathrm{Te}_{x}$ Nanoplatelet Heterostructures Using Band-Offset Tuning. J. Phys. Chem. C 2017, 121 (44), 24816-24823.

(47) Gao, Y.; Li, M.; Delikanli, S.; Zheng, H.; Liu, B.; Dang, C.; Sum, T. C.; Demir, H. V. Low-Threshold Lasing from Colloidal $\mathrm{CdSe} / \mathrm{CdSeTe}$ Core/Alloyed-Crown Type-II Heteronanoplatelets. Nanoscale 2018, 10 (20), 9466-9475.

(48) Kelestemur, Y.; Guzelturk, B.; Erdem, O.; Olutas, M.; Erdem, T.; Usanmaz, C. F.; Gungor, K.; Demir, H. V. CdSe/CdSe ${ }_{1-x} \mathrm{Te}_{x}$ Core/Crown Heteronanoplatelets: Tuning the Excitonic Properties without Changing the Thickness. J. Phys. Chem. C 2017, 121 (8), 4650-4658.

(49) Szemjonov, A.; Pauporté, T.; Ithurria, S. I.; Dubertret, B.; Ciofini, I.; Labat, F. Combined Computational and Experimental Study of CdSeS/ZnS Nanoplatelets: Structural, Vibrational, and Electronic Aspects of Core-Shell Interface Formation. Langmuir 2018, 34 (46), 13828-13836.

(50) Chen, O.; Zhao, J.; Chauhan, V. P.; Cui, J.; Wong, C.; Harris, D. K.; Wei, H.; Han, H.-S.; Fukumura, D.; Jain, R. K.; Bawendi, M. G. Compact High-Quality CdSe-CdS Core-Shell Nanocrystals with Narrow Emission Linewidths and Suppressed Blinking. Nat. Mater. 2013, 12, 445-451.

(51) Zhou, J.; Zhu, M.; Meng, R.; Qin, H.; Peng, X. Ideal CdSe/CdS Core/Shell Nanocrystals Enabled by Entropic Ligands and Their Core Size-, Shell Thickness-, and Ligand-Dependent Photoluminescence Properties. J. Am. Chem. Soc. 2017, 139 (46), 16556-16567.

(52) Reiss, P.; Protière, M.; Li, L. Core/Shell Semiconductor Nanocrystals. Small 2009, 5 (2), 154-168.

(53) Smith, A. M.; Nie, S. Semiconductor Nanocrystals: Structure, Properties, and Band Gap Engineering. Acc. Chem. Res. 2010, 43 (2), 190-200.

(54) Hines, M. A.; Guyot-Sionnest, P. Synthesis and Characterization of Strongly Luminescing ZnS-Capped CdSe Nanocrystals. J. Phys. Chem. 1996, 100 (2), 468-471.

(55) Rowland, C. E.; Fedin, I.; Diroll, B. T.; Liu, Y.; Talapin, D. V.; Schaller, R. D. Elevated Temperature Photophysical Properties and Morphological Stability of CdSe and CdSe/CdS Nanoplatelets. J. Phys. Chem. Lett. 2018, 9 (2), 286-293.

(56) Pandya, R.; Chen, R. Y. S.; Cheminal, A.; Dufour, M.; Richter, J. M.; Thomas, T. H.; Ahmed, S.; Sadhanala, A.; Booker, E. P.; Divitini, G.; Deschler, F.; Greenham, N. C.; Ithurria, S.; Rao, A. Exciton-Phonon Interactions Govern Charge-Transfer-State Dynamics in CdSe/CdTe Two-Dimensional Colloidal Heterostructures. J. Am. Chem. Soc. 2018, 140 (43), 14097-14111.

(57) Mantsevich, V. N.; Smirnov, D. S.; Smirnov, A. M.; Golinskaya, A. D.; Kozlova, M. V.; Saidjonov, B. M.; Dneprovskii, V. S.; Vasiliev, R. B. Nonlinear Light Absorption in Colloidal CdSe/CdS Nanoplatelets. ArXiv e-prints 2018.

(58) Achtstein, A. W.; Marquardt, O.; Scott, R.; Ibrahim, M.; Riedl, T.; Prudnikau, A. V.; Antanovich, A.; Owschimikow, N.; Lindner, J. K. N.; Artemyev, M.; Woggon, U. Impact of Shell Growth on Recombination Dynamics and Exciton-Phonon Interaction in CdSe-CdS Core-Shell Nanoplatelets. ACS Nano 2018, 12 (9), 9476-9483.

(59) Rajadell, F.; Climente, J. I.; Planelles, J. Excitons in Core-Only, Core-Shell and Core-Crown CdSe Nanoplatelets: Interplay Between In-Plane Electron-Hole Correlation, Spatial Confinement, and Dielectric Confinement. Phys. Rev. B: Condens. Matter Mater. Phys. 2017, 96 (3), 035307.

(60) Cassette, E.; Mahler, B.; Guigner, J.-M.; Patriarche, G.; Dubertret, B.; Pons, T. Colloidal CdSe/CdS Dot-in-Plate Nanocrystals with 2D-Polarized Emission. ACS Nano 2012, 6 (8), 6741-6750.

(61) Cassette, E.; Pedetti, S.; Mahler, B.; Ithurria, S.; Dubertret, B.; Scholes, G. D. Ultrafast Exciton Dynamics in 2D In-Plane Hetero- 
Nanostructures: Delocalization and Charge Transfer. Phys. Chem. Chem. Phys. 2017, 19 (12), 8373-8379.

(62) Cruguel, H.; Livache, C.; Martinez, B.; Pedetti, S.; Pierucci, D.; Izquierdo, E.; Dufour, M.; Ithurria, S.; Aubin, H.; Ouerghi, A.; Lacaze, E.; Silly, M. G.; Dubertret, B.; Lhuillier, E. Electronic Structure of CdSe-ZnS 2D Nanoplatelets. Appl. Phys. Lett. 2017, 110 (15), 152103.

(63) Bertrand, G. H. V.; Polovitsyn, A.; Christodoulou, S.; Khan, A. H.; Moreels, I. Shape Control of Zincblende CdSe Nanoplatelets. Chem. Commun. 2016, 52 (80), 11975-11978.

(64) Giovanella, U.; Pasini, M.; Lorenzon, M.; Galeotti, F.; Lucchi, C.; Meinardi, F.; Luzzati, S.; Dubertret, B.; Brovelli, S. Efficient Solution-Processed Nanoplatelet-Based Light-Emitting Diodes with High Operational Stability in Air. Nano Lett. 2018, 18 (6), 34413448.

(65) Xiao, P.; Huang, J.; Yan, D.; Luo, D.; Yuan, J.; Liu, B.; Liang, D. Emergence of Nanoplatelet Light-Emitting Diodes. Materials 2018, 11 (8), 1376.

(66) Chen, Z.; Nadal, B.; Mahler, B.; Aubin, H.; Dubertret, B. Quasi2D Colloidal Semiconductor Nanoplatelets for Narrow Electroluminescence. Adv. Funct. Mater. 2014, 24 (3), 295-302.

(67) Rowland, C. E.; Fedin, I.; Zhang, H.; Gray, S. K.; Govorov, A. O.; Talapin, D. V.; Schaller, R. D. Picosecond Energy Transfer and Multiexciton Transfer Outpaces Auger Recombination in Binary CdSe Nanoplatelet Solids. Nat. Mater. 2015, 14, 484-489.

(68) Scott, R.; Heckmann, J.; Prudnikau, A. V.; Antanovich, A.; Mikhailov, A.; Owschimikow, N.; Artemyev, M.; Climente, J. I.; Woggon, U.; Grosse, N. B.; Achtstein, A. W. Directed Emission of CdSe Nanoplatelets Originating from Strongly Anisotropic 2D Electronic Structure. Nat. Nanotechnol. 2017, 12, 1155-1160.

(69) Kim, W. D.; Kim, D.; Yoon, D.-E.; Lee, H.; Lim, J.; Bae, W. K.; Lee, D. C. Pushing the Efficiency Envelope for Semiconductor Nanocrystal-Based Electroluminescence Devices Using Anisotropic Nanocrystals. Chem. Mater. 2019, 31 (9), 3066-3082.

(70) Liu, B.; Delikanli, S.; Gao, Y.; Dede, D.; Gungor, K.; Demir, H. V. Nanocrystal Light-Emitting Diodes Based on Type II Nanoplatelets. Nano Energy 2018, 47, 115-122.

(71) Luo, S.; Kazes, M.; Lin, H.; Oron, D. Strain-Induced Type II Band Alignment Control in CdSe Nanoplatelet/ZnS-Sensitized Solar Cells. J. Phys. Chem. C 2017, 121 (21), 11136-11143.

(72) Lhuillier, E.; Robin, A.; Ithurria, S.; Aubin, H.; Dubertret, B. Electrolyte-Gated Colloidal Nanoplatelets-Based Phototransistor and Its Use for Bicolor Detection. Nano Lett. 2014, 14 (5), 2715-2719.

(73) Lhuillier, E.; Dayen, J.-F.; Thomas, D. O.; Robin, A.; Doudin, B.; Dubertret, B. Nanoplatelets Bridging a Nanotrench: A New Architecture for Photodetectors with Increased Sensitivity. Nano Lett. 2015, 15 (3), 1736-1742.

(74) Guzelturk, B.; Kelestemur, Y.; Olutas, M.; Delikanli, S.; Demir, H. V. Amplified Spontaneous Emission and Lasing in Colloidal Nanoplatelets. ACS Nano 2014, 8 (7), 6599-6605.

(75) Grim, J. Q.; Christodoulou, S.; Di Stasio, F.; Krahne, R.; Cingolani, R.; Manna, L.; Moreels, I. Continuous-Wave Biexciton Lasing at Room Temperature using Solution-Processed Quantum Wells. Nat. Nanotechnol. 2014, 9, 891-895.

(76) Yang, Z.; Pelton, M.; Fedin, I.; Talapin, D. V.; Waks, E. A Room Temperature Continuous-Wave Nanolaser using Colloidal Quantum Wells. Nat. Commun. 2017, 8 (1), 143.

(77) Altintas, Y.; Gungor, K.; Gao, Y.; Sak, M.; Quliyeva, U.; Bappi, G.; Mutlugun, E.; Sargent, E. H.; Demir, H. V. Giant Alloyed Hot Injection Shells Enable Ultralow Optical Gain Threshold in Colloidal Quantum Wells. ACS Nano 2019, 13 (9), 10662-10670.

(78) Kelestemur, Y.; Olutas, M.; Delikanli, S.; Guzelturk, B.; Akgul, M. Z.; Demir, H. V. Type-II Colloidal Quantum Wells: CdSe/CdTe Core/Crown Heteronanoplatelets. J. Phys. Chem. C 2015, 119 (4), 2177-2185.

(79) Tenne, R.; Pedetti, S.; Kazes, M.; Ithurria, S.; Houben, L.; Nadal, B.; Oron, D.; Dubertret, B. From Dilute Isovalent Substitution to Alloying in CdSeTe Nanoplatelets. Phys. Chem. Chem. Phys. 2016, 18 (22), 15295-15303.
(80) Dufour, M.; Izquierdo, E.; Livache, C.; Martinez, B.; Silly, M. G.; Pons, T.; Lhuillier, E.; Delerue, C.; Ithurria, S. Doping as a Strategy to Tune Color of 2D Colloidal Nanoplatelets. ACS Appl. Mater. Interfaces 2019, 11 (10), 10128-10134.

(81) Szemjonov, A.; Tasso, M.; Ithurria, S.; Ciofini, I.; Labat, F.; Pauporté, T. Ligand exchange on CdSe nanoplatelets for the solar light sensitization of $\mathrm{TiO}_{2}$ and $\mathrm{ZnO}$ nanorod arrays. J. Photochem. Photobiol., A 2019, 368, 182-189.

(82) Kechkeche, D.; Cao, E.; Grazon, C.; Caschera, F.; Noireaux, V.; Baron Niel, M.-L.; Dubertret, B. Semiconductor Nanoplatelets: A New Class of Ultrabright Fluorescent Probes for Cytometric and Imaging Applications. ACS Appl. Mater. Interfaces 2018, 10 (29), 24739-24749.

(83) Dufour, M.; Qu, J.; Greboval, C.; Méthivier, C.; Lhuillier, E.; Ithurria, S. Halide Ligands To Release Strain in Cadmium Chalcogenide Nanoplatelets and Achieve High Brightness. ACS Nano 2019, 13 (5), 5326-5334.

(84) Izquierdo, E.; Dufour, M.; Chu, A.; Livache, C.; Martinez, B.; Amelot, D.; Patriarche, G.; Lequeux, N.; Lhuillier, E.; Ithurria, S. Coupled HgSe Colloidal Quantum Wells through a Tunable Barrier: A Strategy To Uncouple Optical and Transport Band Gap. Chem. Mater. 2018, 30 (12), 4065-4072.

(85) Izquierdo, E.; Robin, A.; Keuleyan, S.; Lequeux, N.; Lhuillier, E.; Ithurria, S. Strongly Confined HgTe 2D Nanoplatelets as Narrow Near-Infrared Emitters. J. Am. Chem. Soc. 2016, 138 (33), 1049610501.

(86) Gréboval, C.; Izquierdo, E.; Livache, C.; Martinez, B.; Dufour, M.; Goubet, N.; Moghaddam, N.; Qu, J.; Chu, A.; Ramade, J.; Aubin, H.; Cruguel, H.; Silly, M.; Lhuillier, E.; Ithurria, S. Impact of Dimensionality and Confinement on the Electronic Properties of Mercury Chalcogenide Nanocrystals. Nanoscale 2019, 11 (9), 39053915.

(87) Bouet, C.; Laufer, D.; Mahler, B.; Nadal, B.; Heuclin, H.; Pedetti, S.; Patriarche, G.; Dubertret, B. Synthesis of Zinc and Lead Chalcogenide Core and Core/Shell Nanoplatelets Using Sequential Cation Exchange Reactions. Chem. Mater. 2014, 26 (9), 3002-3008.

(88) Ithurria, S.; Talapin, D. V. Colloidal Atomic Layer Deposition (c-ALD) using Self-Limiting Reactions at Nanocrystal Surface Coupled to Phase Transfer between Polar and Nonpolar Media. J. Am. Chem. Soc. 2012, 134 (45), 18585-18590.

(89) Hens, Z.; Martins, J. C. A Solution NMR Toolbox for Characterizing the Surface Chemistry of Colloidal Nanocrystals. Chem. Mater. 2013, 25 (8), 1211-1221.

(90) Marbella, L. E.; Millstone, J. E. NMR Techniques for Noble Metal Nanoparticles. Chem. Mater. 2015, 27 (8), 2721-2739.

(91) Morris-Cohen, A. J.; Malicki, M.; Peterson, M. D.; Slavin, J. W. J.; Weiss, E. A. Chemical, Structural, and Quantitative Analysis of the Ligand Shells of Colloidal Quantum Dots. Chem. Mater. 2013, 25 (8), 1155-1165.

(92) Faulkner, R.; DiVerdi, J.; Yang, Y.; Kobayashi, T.; Maciel, G. The Surface of Nanoparticle Silicon as Studied by Solid-State NMR. Materials 2013, 6 (1), 18-46.

(93) Herron, N.; Wang, Y.; Eckert, H. Synthesis and Characterization of Surface-Capped, Size-Quantized Cadmium Sulfide Clusters. Chemical Control of Cluster Size. J. Am. Chem. Soc. 1990, 112 (4), 1322-1326.

(94) Piveteau, L.; Ong, T.-C.; Walder, B. J.; Dirin, D. N.; Moscheni, D.; Schneider, B.; Bär, J.; Protesescu, L.; Masciocchi, N.; Guagliardi, A.; Emsley, L.; Copéret, C.; Kovalenko, M. V. Resolving the Core and the Surface of CdSe Quantum Dots and Nanoplatelets Using Dynamic Nuclear Polarization Enhanced PASS-PIETA NMR Spectroscopy. ACS Cent. Sci. 2018, 4 (9), 1113-1125.

(95) Thayer, A. M.; Steigerwald, M. L.; Duncan, T. M.; Douglass, D. C. NMR Study of Semiconductor Molecular Clusters. Phys. Rev. Lett. 1988, 60 (25), 2673-2676.

(96) Berrettini, M. G.; Braun, G.; Hu, J. G.; Strouse, G. F. NMR Analysis of Surfaces and Interfaces in 2-nm CdSe. J. Am. Chem. Soc. 2004, 126 (22), 7063-7070. 
(97) Piveteau, L.; Ong, T.-C.; Rossini, A. J.; Emsley, L.; Copéret, C.; Kovalenko, M. V. Structure of Colloidal Quantum Dots from Dynamic Nuclear Polarization Surface Enhanced NMR Spectroscopy. J. Am. Chem. Soc. 2015, 137 (43), 13964-13971.

(98) Piveteau, L.; Ong, T.-C.; Rossini, A. J.; Emsley, L.; Copéret, C.; Kovalenko, M. V. Correction to "Structure of Colloidal Quantum Dots from Dynamic Nuclear Polarization Surface Enhanced NMR Spectroscopy. J. Am. Chem. Soc. 2017, 139 (48), 17700-17700.

(99) Lovingood, D. D.; Achey, R.; Paravastu, A. K.; Strouse, G. F. Size- and Site-Dependent Reconstruction in CdSe QDs Evidenced by ${ }^{77} \mathrm{Se}\left\{{ }^{1} \mathrm{H}\right\}$ CP-MAS NMR Spectroscopy. J. Am. Chem. Soc. 2010, 132 (10), 3344-3354.

(100) Tomaselli, M.; Yarger, J. L.; Bruchez, M.; Havlin, R. H.; deGraw, D.; Pines, A.; Alivisatos, A. P. NMR Study of InP Quantum Dots: Surface Structure and Size Effects. J. Chem. Phys. 1999, 110 (18), 8861-8864.

(101) Pines, A.; Gibby, M. G.; Waugh, J. S. Proton-Enhanced NMR of Dilute Spins in Solids. J. Chem. Phys. 1973, 59 (2), 569-590.

(102) Schaefer, J.; Stejskal, E. O. Carbon-13 Nuclear Magnetic Resonance of Polymers Spinning at the Magic Angle. J. Am. Chem. Soc. 1976, 98 (4), 1031-1032.

(103) Rossini, A. J.; Zagdoun, A.; Lelli, M.; Lesage, A.; Copéret, C.; Emsley, L. Dynamic Nuclear Polarization Surface Enhanced NMR Spectroscopy. Acc. Chem. Res. 2013, 46 (9), 1942-1951.

(104) Ni, Q. Z.; Daviso, E.; Can, T. V.; Markhasin, E.; Jawla, S. K.; Swager, T. M.; Temkin, R. J.; Herzfeld, J.; Griffin, R. G. High Frequency Dynamic Nuclear Polarization. Acc. Chem. Res. 2013, 46 (9), 1933-1941.

(105) Kobayashi, T.; Perras, F. A.; Slowing, I. I.; Sadow, A. D.; Pruski, M. Dynamic Nuclear Polarization Solid-State NMR in Heterogeneous Catalysis Research. ACS Catal. 2015, 5 (12), 70557062.

(106) Copéret, C.; Liao, W.-C.; Gordon, C. P.; Ong, T.-C. Active Sites in Supported Single-Site Catalysts: An NMR Perspective. J. Am. Chem. Soc. 2017, 139 (31), 10588-10596.

(107) Lesage, A.; Lelli, M.; Gajan, D.; Caporini, M. A.; Vitzthum, V.; Miéville, P.; Alauzun, J.; Roussey, A.; Thieuleux, C.; Mehdi, A.; Bodenhausen, G.; Coperet, C.; Emsley, L. Surface Enhanced NMR Spectroscopy by Dynamic Nuclear Polarization. J. Am. Chem. Soc. 2010, 132 (44), 15459-15461.

(108) Lelli, M.; Gajan, D.; Lesage, A.; Caporini, M. A.; Vitzthum, V.; Miéville, P.; Héroguel, F.; Rascón, F.; Roussey, A.; Thieuleux, C.; Boualleg, M.; Veyre, L.; Bodenhausen, G.; Coperet, C.; Emsley, L. Fast Characterization of Functionalized Silica Materials by Silicon-29 Surface-Enhanced NMR Spectroscopy Using Dynamic Nuclear Polarization. J. Am. Chem. Soc. 2011, 133 (7), 2104-2107.

(109) Kumar, A.; Walder, B. J.; Kunhi Mohamed, A.; Hofstetter, A.; Srinivasan, B.; Rossini, A. J.; Scrivener, K.; Emsley, L.; Bowen, P. The Atomic-Level Structure of Cementitious Calcium Silicate Hydrate. J. Phys. Chem. C 2017, 121 (32), 17188-17196.

(110) Walder, B. J.; Berk, C.; Liao, W.-C.; Rossini, A. J.; Schwarzwälder, M.; Pradere, U.; Hall, J.; Lesage, A.; Copéret, C.; Emsley, L. One- and Two-Dimensional High-Resolution NMR from Flat Surfaces. ACS Cent. Sci. 2019, 5 (3), 515-523.

(111) Viger-Gravel, J.; Berruyer, P.; Gajan, D.; Basset, J.-M.; Lesage, A.; Tordo, P.; Ouari, O.; Emsley, L. Frozen Acrylamide Gels as Dynamic Nuclear Polarization Matrices. Angew. Chem., Int. Ed. 2017, 56 (30), 8726-8730.

(112) Hanrahan, M. P.; Chen, Y.; Blome-Fernández, R.; Stein, J. L.; Pach, G. F.; Adamson, M. A. S.; Neale, N. R.; Cossairt, B. M.; Vela, J.; Rossini, A. J. Probing the Surface Structure of Semiconductor Nanoparticles by DNP SENS with Dielectric Support Materials. J. Am. Chem. Soc. 2019, 141 (39), 15532-15546.

(113) Silverio, D. L.; Kalkeren, H. A.; Ong, T.-C.; Baudin, M.; Yulikov, M.; Veyre, L.; Berruyer, P.; Chaudhari, S.; Gajan, D.; Baudouin, D.; Cavaillès, M.; Vuichoud, B.; Bornet, A.; Jeschke, G.; Bodenhausen, G.; Lesage, A.; Emsley, L.; Jannin, S.; Thieuleux, C.; Copéret, C. Tailored Polarizing Hybrid Solids with Nitroxide Radicals
Localized in Mesostructured Silica Walls. Helv. Chim. Acta 2017, 100 (6), No. e1700101.

(114) Dixon, W. T. Spinning-Sideband-Free and Spinning-SidebandOnly NMR Spectra in Spinning Samples. J. Chem. Phys. 1982, 77 (4), $1800-1809$.

(115) Antzutkin, O. N.; Shekar, S. C.; Levitt, M. H. TwoDimensional Sideband Separation in Magic-Angle-Spinning NMR. J. Magn. Reson., Ser. A 1995, 115 (1), 7-19.

(116) Walder, B. J.; Dey, K. K.; Kaseman, D. C.; Baltisberger, J. H.; Grandinetti, P. J. Sideband Separation Experiments in NMR with Phase Incremented Echo Train Acquisition. J. Chem. Phys. 2013, 138 (17), 174203.

(117) Autschbach, J. Analyzing NMR shielding tensors calculated with two-component relativistic methods using spin-free localized molecular orbitals. J. Chem. Phys. 2008, 128 (16), 164112.

(118) Bohmann, J. A.; Weinhold, F.; Farrar, T. C. Natural chemical shielding analysis of nuclear magnetic resonance shielding tensors from gauge-including atomic orbital calculations. J. Chem. Phys. 1997, 107 (4), 1173-1184.

(119) Zagdoun, A.; Casano, G.; Ouari, O.; Schwarzwälder, M.; Rossini, A. J.; Aussenac, F.; Yulikov, M.; Jeschke, G.; Copéret, C.; Lesage, A.; Tordo, P.; Emsley, L. Large Molecular Weight Nitroxide Biradicals Providing Efficient Dynamic Nuclear Polarization at Temperatures up to 200 K. J. Am. Chem. Soc. 2013, 135 (34), 12790-12797.

(120) Zagdoun, A.; Rossini, A. J.; Gajan, D.; Bourdolle, A.; Ouari, O.; Rosay, M.; Maas, W. E.; Tordo, P.; Lelli, M.; Emsley, L.; Lesage, A.; Copéret, C. Non-Aqueous Solvents for DNP Surface Enhanced NMR Spectroscopy. Chem. Commun. 2012, 48 (5), 654-656.

(121) Matsuki, Y.; Maly, T.; Ouari, O.; Karoui, H.; Le Moigne, F.; Rizzato, E.; Lyubenova, S.; Herzfeld, J.; Prisner, T.; Tordo, P.; Griffin, R. G. Dynamic Nuclear Polarization with a Rigid Biradical. Angew. Chem., Int. Ed. 2009, 48 (27), 4996-5000.

(122) Maly, T.; Debelouchina, G. T.; Bajaj, V. S.; Hu, K.-N.; Joo, C.G.; Mak-Jurkauskas, M. L.; Sirigiri, J. R.; van der Wel, P. C. A.; Herzfeld, J.; Temkin, R. J.; Griffin, R. G. Dynamic Nuclear Polarization at High Magnetic Fields. J. Chem. Phys. 2008, 128 (5), 052211 .

(123) Wilson, P. J. Density Functional Theory and its Application to Nuclear Magnetic Resonance Shielding Constants. Annu. Rep. NMR Spectrosc. 2003, 49, 117-168.

(124) Gauss, J.; Stanton, J. F. Electron-Correlated Methods for the Calculation of NMR Chemical Shifts. Calculation of NMR and EPR Parameters 2004, 123-139.

(125) Duer, M. J. Introduction to Solid-State NMR Spectroscopy; 2004; p 116-125

(126) Kaupp, M. Interpretation of NMR Chemical Shifts. Calculation of NMR and EPR Parameters 2004, 293-306.

(127) Hens, Z.; Moreels, I.; Martins, J. C. In Situ ${ }^{1}$ H NMR Study on the Trioctylphosphine Oxide Capping of Colloidal InP Nanocrystals. ChemPhysChem 2005, 6 (12), 2578-2584.

(128) Owen, J. S.; Park, J.; Trudeau, P.-E.; Alivisatos, A. P. Reaction Chemistry and Ligand Exchange at Cadmium-Selenide Nanocrystal Surfaces. J. Am. Chem. Soc. 2008, 130 (37), 12279-12281.

(129) Hassinen, A.; Moreels, I.; de Mello Donegá, C.; Martins, J. C.; Hens, Z. Nuclear Magnetic Resonance Spectroscopy Demonstrating Dynamic Stabilization of CdSe Quantum Dots by Alkylamines. J. Phys. Chem. Lett. 2010, 1 (17), 2577-2581.

(130) Gomes, R.; Hassinen, A.; Szczygiel, A.; Zhao, Q.; Vantomme, A.; Martins, J. C.; Hens, Z. Binding of Phosphonic Acids to CdSe Quantum Dots: A Solution NMR Study. J. Phys. Chem. Lett. 2011, 2 (3), $145-152$.

(131) Anderson, N. C.; Hendricks, M. P.; Choi, J. J.; Owen, J. S. Ligand Exchange and the Stoichiometry of Metal Chalcogenide Nanocrystals: Spectroscopic Observation of Facile Metal-Carboxylate Displacement and Binding. J. Am. Chem. Soc. 2013, 135 (49), 1853618548. 
(132) Anderson, N. C.; Owen, J. S. Soluble, Chloride-Terminated CdSe Nanocrystals: Ligand Exchange Monitored by ${ }^{1} \mathrm{H}$ and ${ }^{31} \mathrm{P}$ NMR Spectroscopy. Chem. Mater. 2013, 25 (1), 69-76.

(133) Chen, P. E.; Anderson, N. C.; Norman, Z. M.; Owen, J. S. Tight Binding of Carboxylate, Phosphonate, and Carbamate Anions to Stoichiometric CdSe Nanocrystals. J. Am. Chem. Soc. 2017, 139 (8), 3227-3236.

(134) von Holt, B.; Kudera, S.; Weiss, A.; Schrader, T. E.; Manna, L.; Parak, W. J.; Braun, M. Ligand Exchange of CdSe Nanocrystals Probed by Optical Spectroscopy in the Visible and Mid-IR. J. Mater. Chem. 2008, 18 (23), 2728-2732.

(135) Young, A. G.; Green, D. P.; McQuillan, A. J. Infrared Spectroscopic Studies of Monothiol Ligand Adsorption on CdS Nanocrystal Films in Aqueous Solutions. Langmuir 2006, 22 (26), 11106-11112.

(136) Hostetler, M. J.; Stokes, J. J.; Murray, R. W. Infrared Spectroscopy of Three-Dimensional Self-Assembled Monolayers: NAlkanethiolate Monolayers on Gold Cluster Compounds. Langmuir 1996, 12 (15), 3604-3612.

(137) Badia, A.; Cuccia, L.; Demers, L.; Morin, F.; Lennox, R. B. Structure and Dynamics in Alkanethiolate Monolayers Self-Assembled on Gold Nanoparticles: A DSC, FT-IR, and Deuterium NMR Study. J. Am. Chem. Soc. 1997, 119 (11), 2682-2692.

(138) Boles, M. A.; Ling, D.; Hyeon, T.; Talapin, D. V. The Surface Science of Nanocrystals. Nat. Mater. 2016, 15, 141-153.

(139) Becerra, L. R.; Murray, C. B.; Griffin, R. G.; Bawendi, M. G. Investigation of the Surface Morphology of Capped CdSe Nanocrystallites by ${ }^{31} \mathrm{P}$ Nuclear Magnetic Resonance. J. Chem. Phys. 1994, 100 (4), 3297-3300.

(140) Protesescu, L.; Rossini, A. J.; Kriegner, D.; Valla, M.; de Kergommeaux, A.; Walter, M.; Kravchyk, K. V.; Nachtegaal, M.; Stangl, J.; Malaman, B.; Reiss, P.; Lesage, A.; Emsley, L.; Copéret, C.; Kovalenko, M. V. Unraveling the Core-Shell Structure of LigandCapped $\mathrm{Sn} / \mathrm{SnO}_{\mathrm{x}}$ Nanoparticles by Surface-Enhanced Nuclear Magnetic Resonance, Mössbauer, and X-ray Absorption Spectroscopies. ACS Nano 2014, 8 (3), 2639-2648.

(141) Protesescu, L.; Nachtegaal, M.; Voznyy, O.; Borovinskaya, O.; Rossini, A. J.; Emsley, L.; Copéret, C.; Günther, D.; Sargent, E. H.; Kovalenko, M. V. Atomistic Description of Thiostannate-Capped CdSe Nanocrystals: Retention of Four-Coordinate $\mathrm{SnS}_{4}$ Motif and Preservation of Cd-Rich Stoichiometry. J. Am. Chem. Soc. 2015, 137 (5), 1862-1874.

(142) Rockenberger, J.; Tröger, L.; Rogach, A. L.; Tischer, M.; Grundmann, M.; Eychmüller, A.; Weller, H. The Contribution of Particle Core and Surface to Strain, Disorder and Vibrations in Thiolcapped CdTe Nanocrystals. J. Chem. Phys. 1998, 108 (18), $7807-7815$.

(143) Marcus, M. A.; Flood, W.; Stiegerwald, M.; Brus, L.; Bawendi, M. Structure of Capped Cadmium Selenide Clusters by EXAFS. J. Phys. Chem. 1991, 95 (4), 1572-1576.

(144) Rockenberger, J.; Tröger, L.; Kornowski, A.; Vossmeyer, T.; Eychmüller, A.; Feldhaus, J.; Weller, H. EXAFS Studies on the Size Dependence of Structural and Dynamic Properties of CdS Nanoparticles. J. Phys. Chem. B 1997, 101 (14), 2691-2701.

(145) Berlier, G.; Meneau, F.; Sankar, G.; Catlow, C. R. A.; Thomas, J. M.; Spliethoff, B.; Schüth, F.; Coluccia, S. Synthesis and Characterisation of Small ZnS Particles. Res. Chem. Intermed. 2006, 32 (7), 683-693.

(146) Rockenberger, J.; Tröger, L.; Rogach, A. L.; Tischer, M.; Grundmann, M.; Weller, H.; Eychmüller, A. An EXAFS Study on Thiolcapped CdTe Nanocrystals. Ber. Bunsenges. Phys. Chem. 1998, 102 (11), 1561-1564.

(147) Rossi, T.; Penfold, T. J.; Rittmann-Frank, M. H.; Reinhard, M.; Rittmann, J.; Borca, C. N.; Grolimund, D.; Milne, C. J.; Chergui, M. Characterizing the Structure and Defect Concentration of $\mathrm{ZnO}$ Nanoparticles in a Colloidal Solution. J. Phys. Chem. C 2014, 118 (33), 19422-19430.

(148) Rockenberger, J.; Tröger, L.; Kornowski, A.; Voßmeyer, T.; Eychmüller, A.; Feldhaus, J.; Weller, H. Size Dependence of Structural and Dynamic Properties of CdS-Nanoparticles. Ber. Bunsenges. Phys. Chem. 1997, 101 (11), 1613-1616.

(149) Marcus, M. A.; Brus, L. E.; Murray, C.; Bawendi, M. G.; Prasad, A.; Alivisatos, A. P. EXAFS Studies of Cd Chalcogenide Nanocrystals. Nanostruct. Mater. 1992, 1 (4), 323-335.

(150) Hosokawa, H.; Fujiwara, H.; Murakoshi, K.; Wada, Y.; Yanagida, S.; Satoh, M. In-Situ EXAFS Observation of the Surface Structure of Colloidal CdS Nanocrystallites in N, N-Dimethylformamide. J. Phys. Chem. 1996, 100 (16), 6649-6656.

(151) Hosokawa, H.; Murakoshi, K.; Wada, Y.; Yanagida, S.; Satoh, M. Extended X-ray Absorption Fine Structure Analysis of $\mathrm{ZnS}$ Nanocrystallites in N, N-Dimethylformamide. An Effect of Counteranions on the Microscopic Structure of a Solvated Surface. Langmuir 1996, 12 (15), 3598-3603.

(152) Chemseddine, A.; Fieber-Erdmann, M.; Holub-Krappe, E.; Boulmaaz, S. EXAFS Study of Functionalized Nanoclusters and Nanocluster Assemblies. Z. Phys. D: At., Mol. Clusters 1997, 40 (1), $566-569$.

(153) Doris, S. E.; Lynch, J. J.; Li, C.; Wills, A. W.; Urban, J. J.; Helms, B. A. Mechanistic Insight into the Formation of Cationic Naked Nanocrystals Generated under Equilibrium Control. J. Am. Chem. Soc. 2014, 136 (44), 15702-15710.

(154) Cros-Gagneux, A.; Delpech, F.; Nayral, C.; Cornejo, A.; Coppel, Y.; Chaudret, B. Surface Chemistry of InP Quantum Dots: A Comprehensive Study. J. Am. Chem. Soc. 2010, 132 (51), 1814718157.

(155) Nag, A.; Kovalenko, M. V.; Lee, J.-S.; Liu, W.; Spokoyny, B.; Talapin, D. V. Metal-free Inorganic Ligands for Colloidal Nanocrystals: $\mathrm{S}^{2-}, \mathrm{HS}^{-}, \mathrm{Se}^{2-}, \mathrm{HSe}^{-}, \mathrm{Te}^{2-}, \mathrm{HTe}^{-}, \mathrm{TeS}_{3}{ }^{2-}, \mathrm{OH}^{-}$, and $\mathrm{NH}_{2}{ }^{-}$as Surface Ligands. J. Am. Chem. Soc. 2011, 133 (27), 10612-10620.

(156) Kovalenko, M. V.; Scheele, M.; Talapin, D. V. Colloidal Nanocrystals with Molecular Metal Chalcogenide Surface Ligands. Science 2009, 324 (5933), 1417-1420.

(157) Benchamekh, R.; Gippius, N. A.; Even, J.; Nestoklon, M. O.; Jancu, J. M.; Ithurria, S.; Dubertret, B.; Efros, A. L.; Voisin, P. TightBinding Calculations of Image-Charge Effects in Colloidal Nanoscale Platelets of CdSe. Phys. Rev. B: Condens. Matter Mater. Phys. 2014, 89 (3), 035307.

(158) Ithurria, S.; Bousquet, G.; Dubertret, B. Continuous Transition from $3 \mathrm{D}$ to $1 \mathrm{D}$ Confinement Observed during the Formation of CdSe Nanoplatelets. J. Am. Chem. Soc. 2011, 133 (9), 3070-3077.

(159) Koster, R. S.; Fang, C.; van Blaaderen, A.; Dijkstra, M.; van Huis, M. A. Acetate Ligands Determine the Crystal Structure of CdSe Nanoplatelets - a Density Functional Theory Study. Phys. Chem. Chem. Phys. 2016, 18 (32), 22021-22024.

(160) Jiang, Y.; Ojo, W.-S.; Mahler, B.; Xu, X.; Abécassis, B.; Dubertret, B. Synthesis of CdSe Nanoplatelets without Short-Chain Ligands: Implication for Their Growth Mechanisms. ACS Omega 2018, 3 (6), 6199-6205.

(161) Lyashchova, A.; Dmytruk, A.; Dmitruk, I.; Klimusheva, G.; Mirnaya, T.; Asaula, V. Optical Absorption, Induced Bleaching, and Photoluminescence of CdSe Nanoplatelets Grown in Cadmium Octanoate Matrix. Nanoscale Res. Lett. 2014, 9 (1), 88.

(162) Chen, Y.; Chen, D.; Li, Z.; Peng, X. Symmetry-Breaking for Formation of Rectangular CdSe Two-Dimensional Nanocrystals in Zinc-Blende Structure. J. Am. Chem. Soc. 2017, 139 (29), 1000910019.

(163) Szemjonov, A.; Pauporte, T.; Ithurria, S.; Lequeux, N.; Dubertret, B.; Ciofini, I.; Labat, F. Ligand-Stabilized CdSe Nanoplatelet Hybrid Structures with Tailored Geometric and Electronic Properties. New Insights from Theory. RSC Adv. 2014, 4 (99), 55980-55989.

(164) Singh, S.; Tomar, R.; ten Brinck, S.; De Roo, J.; Geiregat, P.; Martins, J. C.; Infante, I.; Hens, Z. Colloidal CdSe Nanoplatelets, a Model for Surface Chemistry/Opto-Electronic Property Relations in Semiconductor Nanocrystals. J. Am. Chem. Soc. 2018, 140 (41), 13292-13300. 
(165) Zagdoun, A.; Rossini, A. J.; Conley, M. P.; Grüning, W. R.; Schwarzwälder, M.; Lelli, M.; Franks, W. T.; Oschkinat, H.; Copéret, C.; Emsley, L.; Lesage, A. Improved Dynamic Nuclear Polarization Surface-Enhanced NMR Spectroscopy through Controlled Incorporation of Deuterated Functional Groups. Angew. Chem., Int. Ed. 2013, 52 (4), 1222-1225.

(166) Ratcliffe, C. I.; Yu, K.; Ripmeester, J. A.; Badruz Zaman, M.; Badarau, C.; Singh, S. Solid State NMR Studies of Photoluminescent Cadmium Chalcogenide Nanoparticles. Phys. Chem. Chem. Phys. 2006, 8 (30), 3510-3519.

(167) Shatlock, M. P.; Maciel, G. E. Cadmium-113 NMR Investigations of Cadmium Oxide. J. Chem. Phys. 1984, 81 (2), $895-902$.

(168) Widdifield, C. M.; Schurko, R. W. Understanding Chemical Shielding Tensors Using Group Theory, MO Analysis, and Modern Density-Functional Theory. Concepts Magn. Reson., Part A 2009, 34A (2), $91-123$.

(169) Gordon, C. P.; Raynaud, C.; Andersen, R. A.; Copéret, C.; Eisenstein, O. Carbon-13 NMR Chemical Shift: A Descriptor for Electronic Structure and Reactivity of Organometallic Compounds. Acc. Chem. Res. 2019, 52 (8), 2278-2289.

(170) Gordon, C. P.; Andersen, R. A.; Copéret, C. Metal Olefin Complexes: Revisiting the Dewar-Chatt-Duncanson Model and Deriving Reactivity Patterns from Carbon-13 NMR Chemical Shift. Helv. Chim. Acta 2019, 102 (9), No. e1900151.

(171) Lantto, P.; Vaara, J.; Kantola, A. M.; Telkki, V.-V.; Schimmelpfennig, B.; Ruud, K.; Jokisaari, J. Relativistic Spin-Orbit Coupling Effects on Secondary Isotope Shifts of ${ }^{13} \mathrm{C}$ Nuclear Shielding in $\mathrm{CX}_{2}(\mathrm{X}=\mathrm{O}, \mathrm{S}, \mathrm{Se}, \mathrm{Te})$. J. Am. Chem. Soc. 2002, 124 (11), 2762-2771.

(172) Vícha, J.; Komorovsky, S.; Repisky, M.; Marek, R.; Straka, M. Relativistic Spin-Orbit Heavy Atom on the Light Atom NMR Chemical Shifts: General Trends Across the Periodic Table Explained. J. Chem. Theory Comput. 2018, 14 (6), 3025-3039. 